\title{
Isotopic composition for source identification of mercury in atmospheric fine particles
}

\author{
Qiang Huang ${ }^{1}$, Jiubin Chen ${ }^{1}$, Weilin Huang ${ }^{2}$, Pingqing Fu ${ }^{3}$, Benjamin Guinot ${ }^{4}$, Xinbin Feng ${ }^{1}$, Lihai Shang ${ }^{1}$, \\ Zhuhong Wang ${ }^{1}$, Zhongwei Wang ${ }^{1}$, Shengliu Yuan ${ }^{1}$, Hongming Cai ${ }^{1}$, Lianfang Wei ${ }^{3}$, and Ben Yu ${ }^{1}$ \\ ${ }^{1}$ SKLEG, Institute of Geochemistry, Chinese Academy of Sciences, Guiyang 550081, China \\ ${ }^{2}$ Department of Environmental Sciences, Rutgers, The State University of New Jersey, New Brunswick, NJ 08901, USA \\ ${ }^{3}$ LAPC, Institute of Atmospheric Physics, Chinese Academy of Sciences, Beijing 100029, China \\ ${ }^{4}$ Laboratoire d'Aérologie UMR5560 CNRS-Université Toulouse 3, Toulouse, France
}

Correspondence to: Jiubin Chen (chenjiubin@vip.gyig.ac.cn)

Received: 29 April 2016 - Published in Atmos. Chem. Phys. Discuss.: 8 June 2016

Revised: 9 September 2016 - Accepted: 10 September 2016 - Published: 22 September 2016

\begin{abstract}
The usefulness of mercury $(\mathrm{Hg})$ isotopes for tracing the sources and pathways of $\mathrm{Hg}$ (and its vectors) in atmospheric fine particles $\left(\mathrm{PM}_{2.5}\right)$ is uncertain. Here, we measured $\mathrm{Hg}$ isotopic compositions in 30 potential source materials and $23 \mathrm{PM}_{2.5}$ samples collected in four seasons from the megacity Beijing (China) and combined the seasonal variation in both mass-dependent fractionation (represented by the ratio ${ }^{202} \mathrm{Hg} /{ }^{198} \mathrm{Hg}, \delta^{202} \mathrm{Hg}$ ) and mass-independent fractionation of isotopes with odd and even mass numbers (represented by $\Delta^{199} \mathrm{Hg}$ and $\Delta^{200} \mathrm{Hg}$, respectively) with geochemical parameters and meteorological data to identify the sources of $\mathrm{PM}_{2.5}-\mathrm{Hg}$ and possible atmospheric particulate $\mathrm{Hg}$ transformation. All $\mathrm{PM}_{2.5}$ samples were highly enriched in $\mathrm{Hg}$ and other heavy metals and displayed wide ranges of both $\delta^{202} \mathrm{Hg}(-2.18$ to $0.51 \%$ o $)$ and $\Delta^{199} \mathrm{Hg}$ $(-0.53$ to $0.57 \%)$, as well as small positive $\Delta^{200} \mathrm{Hg}(0.02$ to $0.17 \%$ ). The results indicated that the seasonal variation in $\mathrm{Hg}$ isotopic composition (and elemental concentrations) was likely derived from variable contributions from anthropogenic sources, with continuous input due to industrial activities (e.g., smelting, cement production and coal combustion) in all seasons, whereas coal combustion dominated in winter and biomass burning mainly found in autumn. The more positive $\Delta^{199} \mathrm{Hg}$ of $\mathrm{PM}_{2.5}-\mathrm{Hg}$ in spring and early summer was likely derived from long-range-transported $\mathrm{Hg}$ that had undergone extensive photochemical reduction. The study demonstrated that $\mathrm{Hg}$ isotopes may be potentially used for tracing the sources of particulate $\mathrm{Hg}$ and its vectors in the atmosphere.
\end{abstract}

\section{Introduction}

Mercury $(\mathrm{Hg})$ is a globally distributed hazardous metal and is well known for its long-range transport, environmental persistence and toxicity (Kim et al., 2009; Selin, 2009; Schleicher et al., 2015). Hg is emitted to the atmosphere through natural and anthropogenic processes or reemission of previously deposited legacy $\mathrm{Hg}$. It has three operationally defined forms: gaseous elemental $\mathrm{Hg}$ (GEM), reactive gaseous $\mathrm{Hg}$ (RGM) and particle-bound Hg (PBM) (Selin, 2009). In general, GEM ( $>90 \%$ of the total $\mathrm{Hg}$ in atmosphere) is fairly stable and can be transported globally, whereas RGM is rapidly deposited from the atmosphere in wet and dry deposition, and PBM is assumed to be transported more regionally (Selin, 2009; Fu et al., 2012). Recent measurements of PBM in several rural and urban areas have shown that $\mathrm{Hg}$ associated with particulate matter $(\mathrm{PM})$ of size $<2.5 \mu \mathrm{m}\left(\mathrm{PM}_{2.5}-\mathrm{Hg}\right)$ has typical concentrations $<100 \mathrm{pg} \mathrm{m}^{-3}$ in background atmospheric environments (Liu et al., 2007; Fu et al., 2008; Kim et al., 2012), but exceeds $300 \mathrm{pg} \mathrm{m}^{-3}$ in contaminated regions (Xiu et al., 2009; Zhu et al., 2014). $\mathrm{PM}_{2.5}-\mathrm{Hg}$ is of particular concern because, once inhaled, both $\mathrm{Hg}$ and its vectors might have adverse effects on human beings.

Mercury has seven stable isotopes $\left({ }^{196} \mathrm{Hg},{ }^{198} \mathrm{Hg}\right.$, ${ }^{199} \mathrm{Hg},{ }^{200} \mathrm{Hg},{ }^{201} \mathrm{Hg},{ }^{202} \mathrm{Hg}$ and ${ }^{204} \mathrm{Hg}$ ) and its isotopic ratios in the nature have attracted much interest in recent years (Yin et al., 2010; Hintelmann and Zheng, 2012; Blum et al., 2014; Cai and Chen, 2016). Previous studies have reported both mass-dependent fractionation (MDF, $\delta^{202} \mathrm{Hg}$ ) and mass- 
independent fractionation (MIF, primarily observation of odd atomic weighed $\mathrm{Hg}$ isotopes, $\Delta^{199} \mathrm{Hg}$ and $\Delta^{201} \mathrm{Hg}$ ) of $\mathrm{Hg}$ isotopes in environments (Hintelmann and Lu, 2003; Jackson et al., 2004, 2008; Bergquist and Blum, 2007; Gratz et al., 2010; Chen et al., 2012; Sherman et al., 2012). The nuclear volume effect (NVE) (Schauble, 2007) and magnetic isotope effect (MIE) (Buchachenko, 2009) are thought to be the main causes for odd-MIF (Bergquist and Blum, 2007; Gratz et al., 2010; Wiederhold et al., 2010; Sonke, 2011; Chen et al., 2012; Ghosh et al., 2013; Eiler et al., 2014). Theoretical and experimental data suggested a $\Delta^{199} \mathrm{Hg} / \Delta^{201} \mathrm{Hg}$ ratio about 1.6 for NVE (Zheng and Hintelmann, 2009, 2010b), and a $\Delta^{199} \mathrm{Hg} / \Delta^{201} \mathrm{Hg}$ ratio mostly between 1.0 and 1.3 for MIE as a result of photolytic reductions under aquatic (and atmospheric) conditions (Zheng and Hintelmann, 2009, 2010a; Malinovsky et al., 2010; Wiederhold et al., 2010; Sonke, 2011; Ghosh et al., 2013; Eiler et al., 2014). Over the past decade, studies have indicated that $\mathrm{Hg}$ isotope ratios are useful for differentiating Hg sources in terrestrial samples, such as sediments (Jackson et al., 2004; Feng et al., 2010; Ma et al., 2013), soils (Biswas et al., 2008; Zhang et al., 2013a) and biota (Sherman et al., 2013; Yin et al., 2013; Jackson, 2015), and for distinguishing potential biogeochemical processes that $\mathrm{Hg}$ had undergone (Jackson et al., 2013; Sherman et al., 2013; Yin et al., 2013; Masbou et al., 2015). Up to now, several studies have reported $\mathrm{Hg}$ isotopic compositions in atmospheric samples (Zambardi et al., 2009; Gratz et al., 2010; Chen et al., 2012; Sherman et al., 2012, 2015; Demers et al., 2013, 2015a; Rolison et al., 2013; Fu et al., 2014, 2016; Yuan et al., 2015; Das et al., 2016; Enrico et al., 2016). These studies reported large variations in $\Delta^{199} \mathrm{Hg}$ and $\delta^{202} \mathrm{Hg}$ values for GEM (ranging from -0.41 to $0.06 \%$ for $\Delta^{199} \mathrm{Hg}$, and from -3.88 to $1.43 \%$ for $\delta^{202} \mathrm{Hg}$ ) (Zambardi et al., 2009; Gratz et al., 2010; Sherman et al., 2010; Rolison et al., 2013; Yin et al., 2013; Demers et al., 2015b; Das et al., 2016; Enrico et al., 2016; Fu et al., 2016) and for $\mathrm{Hg}$ in precipitation (from 0.04 to $1.16 \%$ for $\Delta^{199} \mathrm{Hg}$, and from -4.37 to $1.48 \%$ o for $\delta^{202} \mathrm{Hg}$ ) (Gratz et al., 2010; Chen et al., 2012; Sherman et al., 2012, 2015; Demers et al., 2013; Wang et al., 2015b; Yuan et al., 2015). In addition, recent studies have found MIF of even $\mathrm{Hg}$ isotopes (even-MIF, $\Delta^{200} \mathrm{Hg}$ ) in natural samples mainly related to the atmosphere, rendering $\mathrm{Hg}$ a unique heavy metal having "three-dimensional" isotope systems (Chen et al., 2012).

While Hg isotopes in both GEM and RGM have drawn much attention, those of PBM are comparably less studied in the literature. Indeed, only several prior studies have focused on Hg isotopes in PBM. Rolison et al. (2013) reported, for the first time, $\delta^{202} \mathrm{Hg}$ (of -1.61 to $-0.12 \%$ ) and $\Delta^{199} \mathrm{Hg}$ values (of 0.36 to $1.36 \%$ ) for PBM from the Grand Bay area in the USA, and the ratios of $\Delta^{199} \mathrm{Hg} / \Delta^{201} \mathrm{Hg}$ close to 1 that was thought to be derived from in-aerosol photoreduction. Huang et al. (2015) measured $\mathrm{Hg}$ isotope ratios for two $\mathrm{PM}_{2.5}$ samples taken from Guiyang, China, with $\delta^{202} \mathrm{Hg}$ of -1.71 and $-1.13 \%$ and $\Delta^{199} \mathrm{Hg}$ of 0.21 and $0.16 \%$. Das et al. (2016) measured $\mathrm{Hg}$ isotopic compositions of PBM in $\mathrm{PM}_{10}$ from Kolkata, eastern India, and found negative MDF and varied values of $\Delta^{199} \mathrm{Hg}$ between -0.31 and $0.33 \%$ o. These studies showed that the $\mathrm{Hg}$ isotope approach could be developed for tracking the sources and pathways of $\mathrm{Hg}$ species in the atmosphere.

China is one of the largest $\mathrm{Hg}$ emission countries in the world (Fu et al., 2012; Zhang et al., 2015), with a total estimated anthropogenic $\mathrm{Hg}$ emission of approximately $356 \mathrm{t}$ in 2000 and $538 \mathrm{t}$ in 2010 (Zhang et al., 2015). Coal combustion, nonferrous metal smelting, and cement production are the dominant $\mathrm{Hg}$ emission sources in China (collectively accounting for approximately over $80 \%$ of the total $\mathrm{Hg}$ emission) (Zhang et al., 2015). Haze particles, especially $\mathrm{PM}_{2.5}$, which are among the most serious atmospheric pollutants in urban areas of China (Huang et al., 2014), are important carriers of $\mathrm{Hg}$ (Lin et al., 2015b; Schleicher et al., 2015). If $\mathrm{PM}_{2.5}$ is emitted from the same source as $\mathrm{Hg}$ (Huang et al., 2014; Lin et al., 2015b; Schleicher et al., 2015; Zhang et al., 2015), quantifying $\mathrm{Hg}$ isotopes may provide direct evidence for the sources of both $\mathrm{Hg}$ and $\mathrm{PM}_{2.5}$, as well as insight into the geochemical processes that they may have undergone.

In this study, we attempted to identify the sources of $\mathrm{PM}_{2.5}-\mathrm{Hg}$ in Beijing, the capital of China, using $\mathrm{Hg}$ isotopic composition coupled with meteorological and other geochemical parameters. We selected Beijing as the study site because, like many other Chinese megacities, Beijing has suffered severe $\mathrm{PM}_{2.5}$ pollution (Huang et al., 2014; Gao et al., 2015) and is considered as the most PBM polluted area in China (Schleicher et al., 2015). In the past decade, only a few prior studies quantified the $\mathrm{Hg}$ concentrations in $\mathrm{PM}_{2.5}$ samples collected from Beijing (Wang et al., 2006; Zhang et al., 2013b; Schleicher et al., 2015), while no research attempted to track its sources using the $\mathrm{Hg}$ isotope approach. The specific objectives of this study were (1) to characterize the seasonal variation in $\mathrm{Hg}$ isotope compositions in $\mathrm{PM}_{2.5}$ of Beijing and (2) to test the effectiveness of the $\mathrm{Hg}$ isotope technique for tracking the sources of the $\mathrm{PM}_{2.5}-\mathrm{Hg}$.

\section{Materials and methods}

\subsection{Field site and sampling method}

Beijing $\left(39.92^{\circ} \mathrm{N}\right.$ and $\left.116.46^{\circ} \mathrm{E}\right)$ has a population of over 21 million. It is located in a temperate warm zone with typical continental monsoon climate. The northwestern part of the greater Beijing metropolitan area is mountainous, while the southeastern part is flat. It has an average annual temperature of about $11.6^{\circ} \mathrm{C}$, with a mean value of $24^{\circ} \mathrm{C}$ in summer and $-2^{\circ} \mathrm{C}$ in winter. In the summer, the wind blows mainly from the southeast under the influence of the hot and humid East Asian monsoon, whereas the cold and dry monsoon blows from Siberia and Mongolia in the winter. The winter heating 
season in Beijing normally starts on 15 November and ends on 15 March.

$\mathrm{PM}_{2.5}$ was sampled from September 2013 to July 2014 using a high-volume $\mathrm{PM}_{2.5}$ sampler placed on the roof of a building (approximately $8 \mathrm{~m}$ above the ground) of the Institute of Atmospheric Physics, Chinese Academy of Sciences, which is located between the north 3rd and 4th ring of Beijing. The meteorological model showed that the arriving air masses were transported mainly by two directions, with the northwest winds dominant in winter and the southern winds mainly in summer. The sampling information is detailed in the Supplement (see Table S1). The $\mathrm{PM}_{2.5}$ samples were collected using a Tisch Environmental $\mathrm{PM}_{2.5}$ highvolume air sampler, which collects particles at a flow rate of $1.0 \mathrm{~m}^{3} \mathrm{~min}^{-1}$ through a $\mathrm{PM}_{2.5}$ size-selective inlet. As the particles travel through the size selective inlet the larger particles are trapped inside of the inlet, while the smaller-size $\left(\mathrm{PM}_{2.5}\right)$ particles continue to travel through the $\mathrm{PM}_{2.5}$ inlet and are collected on a pre-combusted $\left(450^{\circ} \mathrm{C}\right.$ for $\left.6 \mathrm{~h}\right)$ quartz fiber filter (Pallflex 2500 QAT-UP, $20 \mathrm{~cm} \times 25 \mathrm{~cm}$, Pallflex Product Co., USA). The mass of $\mathrm{PM}_{2.5}$ on each filter was measured using a gravimetric method by the mass difference before and after sampling. The filters were conditioned in a chamber with a relative humidity of about $48 \%$ and a temperature of $20 \pm 2{ }^{\circ} \mathrm{C}$ for about $24 \mathrm{~h}$ before and after sampling. A field blank was also collected during sampling and the value $(<0.2 \mathrm{ng}$ of $\mathrm{Hg}, n=6)$ was negligible $(<2 \%)$ compared to the total $\mathrm{Hg}$ mass contained in the $\mathrm{PM}_{2.5}$ samples. After sampling, each filter was recovered, wrapped with a pre-combusted (to eliminate $\mathrm{Hg}$ ) aluminum film, and packed in a sealed plastic bag. The filters were brought back to the laboratory and stored at $-20^{\circ} \mathrm{C}$ prior to analysis.

In order to better assign sources of $\mathrm{Hg}$, we collected and measured 30 solid samples of different materials that may be potential $\mathrm{Hg}$ (and $\mathrm{PM}_{2.5}$ ) sources and that may contribute to $\mathrm{PM}_{2.5}-\mathrm{Hg}$ in Beijing. They included (i) 8 samples (including feed coal powder, bottom ash, desulfurization gypsum and fly ash) from two coal-fired power plants (from Hubei and Mongolia provinces); (ii) 6 samples from a $\mathrm{Pb}-\mathrm{Zn}$ smelting plant (including blast furnace dust, dust of blast furnace slag, sintering dust, coke, return powder and agglomerate); (iii) 10 samples from a cement plant (including coal powder, raw meal, sandstone, clay, limestone, steel slag, sulfuric acid residue, desulfurization gypsum and cement clinker), 6 of which have been published previously (Wang et al., 2015b); (iv) 4 topsoil samples (surface horizon: organics mixed with mineral matter, these samples are not natural soil on typical soil profiles) from the Beijing center city (Olympic Park, Beihai Park, the Winter Palace and Renmin University of China (RUC)) and 2 dust samples from RUC (one building roof dust and one road dust); (v) 1 total suspended particle (TSP; the sampling of TSP was carried out using an inhouse-constructed low-volume (about $1.8 \mathrm{~m}^{3} \mathrm{~h}^{-1}$ ) air sampler equipped with a TSP inlet, and a pre-cleaned mixed fiber filter $(47 \mathrm{~mm})$ was used for the TSP low-volume inlets) sam- ple from the atmosphere of a rural area of Yanqing district, northwest of Beijing; and (vi) 2 urban road dust, 2 suburban road dust and 1 suburban topsoil samples from the city of Shijiazhuang, southwest of Beijing. Though automobile exhaust might also be a contributing source of $\mathrm{PM}_{2.5}-\mathrm{Hg}$, we were not able to measure its $\mathrm{Hg}$ isotope ratios due to its exceedingly low $\mathrm{Hg}$ concentration (Won et al., 2007).

\subsection{Materials and reagents}

Materials and reagents used in this study were similar to those described in a previous study (Huang et al., 2015). A $0.2 \mathrm{M} \mathrm{BrCl}$ solution was prepared by mixing the distilled concentrated $\mathrm{HCl}$ with pre-heated $\left(250^{\circ} \mathrm{C}, 12 \mathrm{~h}\right) \mathrm{KBr}$ and $\mathrm{KBrO}_{3}$ powders. Two $\mathrm{SnCl}_{2}$ solutions of 20 and $3 \%(\mathrm{wt})$ were prepared by dissolving in $1 \mathrm{M} \mathrm{HCl}$ and were used for online reduction of $\mathrm{Hg}$ for concentration and isotope measurements, respectively. A $20 \%$ (wt) $\mathrm{NH}_{2} \mathrm{OH} \cdot \mathrm{HCl}$ solution was used for $\mathrm{BrCl}$ neutralization.

Two international Hg standards NIST SRM 3133 and UMAlmaden were used as the reference materials for $\mathrm{Hg}$ isotope analysis. NIST SRM 997 thallium $\left(20 \mathrm{ng} \mathrm{mL}^{-1} \mathrm{Tl}\right.$ in $3 \%$ $\mathrm{HNO}_{3}$ ) was employed for mass bias correction (Chen et al., 2010; Huang et al., 2015). Two other reference materials, the solution Fluka $28941 \mathrm{Hg}$ (TraceCERT ${ }^{\circledR}$, Sigma-Aldrich) and the soil GBW07405 (National Center for Standard Materials, Beijing, China), were used as in-house isotope standards, and these were regularly measured for quality control of $\mathrm{Hg}$ concentration and isotope measurements. It is worth noting that Fluka $28941 \mathrm{Hg}$ is a standard different from ETH Fluka $\mathrm{Hg}$ (Jiskra et al., 2012; Smith et al., 2015).

\subsection{Isotopic composition analysis}

Mercury bound to $\mathrm{PM}_{2.5}$ and solid source materials was released via a dual-stage combustion protocol and was captured in a $5 \mathrm{~mL} 40 \%$ acid mixture $(2: 4: 9$ volumetric ratio of $10 \mathrm{M} \mathrm{HCl}, 15 \mathrm{M} \mathrm{HNO}_{3}$ and Milli-Q water) (Huang et al., 2015). The detailed procedure is available in Huang et al. (2015). In brief, the filter samples were rolled into a cylinder and placed in a furnace quartz tube $(25 \mathrm{~mm}$ OD, $22 \mathrm{~mm}$ ID, $1.0 \mathrm{~m}$ length), which was located in two series of combustion tube furnaces (BTF-1200C-S, Anhui BEQ Equipment Technology Ltd., China). The solid source samples were powdered, weighed and put into a sample quartz tube (20 mm OD, $18 \mathrm{~mm} \mathrm{ID,} 10 \mathrm{~cm}$ length), which was capped with quartz wool (pre-cleaned at $500^{\circ} \mathrm{C}$ ) at both ends to prevent particle emission. The sample tube was then placed into the large quartz tube of the furnace. The samples were combusted through a temperature-programmed routine in the dual-stage combustion and acid solution trapping system. An aliquot $(50 \mu \mathrm{L})$ of $0.2 \mathrm{M} \mathrm{BrCl}$ was added to the above trapping solution to stabilize the $\mathrm{Hg}^{2+}$. The trapping solution for each sample was diluted to a final acid concentration of about $20 \%$ and was stored at $4{ }^{\circ} \mathrm{C}$ for the subsequent $\mathrm{Hg}$ concen- 
tration and isotope measurement. The accuracy and precision of the dual-stage combustion protocol were evaluated by the analysis of the certified reference material GBW07405 using the same digestion method. The detectable $\mathrm{Hg}$ in the procedural blank ( $<0.2 \mathrm{ng}, n=12)$ of this dual-stage combustion method was negligible compared to the amount of total $\mathrm{Hg}$ (> $5 \mathrm{ng}$ ) in both $\mathrm{PM}_{2.5}$ samples and procedural standards.

Mercury isotope analyses were performed on the MC-ICPMS (Nu Instruments Ltd., UK) at the State Key Laboratory of Environmental Geochemistry, Institute of Geochemistry, China. The details of the analytical procedures and the instrumental settings were given in previous studies (Huang et al., 2015; Lin et al., 2015a; Wang et al., 2015b; Yuan et al., 2015). In brief, a home-made cold-vapor generation system was coupled with an Aridus II desolvating nebulizer for respective $\mathrm{Hg}$ and $\mathrm{Tl}$ introductions. The Faraday cups were positioned to simultaneously collect five $\mathrm{Hg}$ isotopes and two $\mathrm{Tl}$ isotopes, including ${ }^{205} \mathrm{Tl}(\mathrm{H} 3),{ }^{203} \mathrm{Tl}(\mathrm{H} 1),{ }^{202} \mathrm{Hg}$ (Ax), ${ }^{201} \mathrm{Hg}$ (L1), ${ }^{200} \mathrm{Hg}$ (L2), ${ }^{199} \mathrm{Hg}$ (L3), and ${ }^{198} \mathrm{Hg}$ (L4). The instrumental mass bias was double-corrected by both internal standard NIST SRM $997 \mathrm{Tl}$ and by sample-standard bracketing (SSB) using the international standard NIST SRM $3133 \mathrm{Hg}$. The MDF of isotopes is represented by delta $(\delta)$ notation in units of permil $(\% \circ)$ and defined as the following equation (Blum and Bergquist, 2007):

$$
\begin{aligned}
\delta^{x} \mathrm{Hg}(\% o) & =\left[\left({ }^{x} \mathrm{Hg} /{ }^{198} \mathrm{Hg}\right)_{\text {sample }} /\left({ }^{x} \mathrm{Hg} /{ }^{198} \mathrm{Hg}\right)_{\text {NIST3133 }}\right. \\
& -1] \times 1000
\end{aligned}
$$

where $x=199,200,201$, and 202. MIF is reported as the deviation of a measured delta value from the theoretically predicted value due to kinetic MDF according to the following equation:

$$
\Delta^{x} \mathrm{Hg}(\% \circ)=\delta^{x} \mathrm{Hg}-\beta \times \delta^{202} \mathrm{Hg},
$$

where the mass-dependent scaling factor $\beta$ is of about 0.252 , 0.5024 and 0.752 for ${ }^{199} \mathrm{Hg},{ }^{200} \mathrm{Hg}$ and ${ }^{201} \mathrm{Hg}$, respectively (Blum and Bergquist, 2007).

The Fluka $28941 \mathrm{Hg}$ standard was carefully calibrated against the NIST SRM $3133 \mathrm{Hg}$ and the long-term measurements yielded an average value of $-1.00 \pm 0.13 \%$ ( $2 \mathrm{SD}$, $n=15)$ for $\delta^{202} \mathrm{Hg}$, with a precision similar to that $(0.10 \%$, $n=114$ ) obtained for NIST SRM $3133 \mathrm{Hg}$. Our repeated measurements of UM-Almaden and GBW07405 had average $\delta^{202} \mathrm{Hg}, \Delta^{199} \mathrm{Hg}$ and $\Delta^{201} \mathrm{Hg}$ values of $-0.60 \pm 0.09$, $-0.01 \pm 0.06$ and $-0.03 \pm 0.06 \%$ ( $2 \mathrm{SD}, n=18)$ and of $-1.77 \pm 0.14,-0.29 \pm 0.04$ and $-0.32 \pm 0.06 \%$ ( $2 \mathrm{SD}$, $n=6$ ), respectively, consistent with the data published in previous studies (Blum and Bergquist, 2007; Zheng et al., 2007; Smith et al., 2008; Carignan et al., 2009; Zambardi et al., 2009; Chen et al., 2010; Sherman et al., 2010; Wiederhold et al., 2010; Huang et al., 2015). In this study, the 2 SD uncertainties $\left(0.14,0.04\right.$ and $0.06 \%$ for $\delta^{202} \mathrm{Hg}, \Delta^{199} \mathrm{Hg}$ and $\Delta^{201} \mathrm{Hg}$ ) obtained for the soil reference GBW07405 were considered as the typical external uncertainties for some $\mathrm{PM}_{2.5}$ samples that were measured only once due to their limited mass. Otherwise, the uncertainties were calculated based on the multiple measurements (Tables S1 and S2).

\subsection{Concentration measurements}

A small fraction of each trapping solution (20\% acid mixture) was used to measure the $\mathrm{Hg}$ concentration by cold-vapor atomic fluorescence spectroscopy (Tekran 2500, Tekran $^{\circledR}$ Instruments Corporation, CA), with a precision better than $10 \%$. The recoveries of $\mathrm{Hg}$ for the standard GBW07405 and 30 solid samples were in the acceptable range of 95 to $105 \%$, but no recovery of $\mathrm{Hg}$ for the $\mathrm{PM}_{2.5}$ samples was determined due to limited availability of the samples. A $0.5 \mathrm{~cm}^{2}$ punch from each filter sample was analyzed for organic and elemental carbon (OC / EC) with a Desert Research Institute (DRI) model 2001 thermal-optical carbon analyzer (Atmoslytic Inc., Calabasas, CA, USA) following the Interagency Monitoring of Protected Visual Environments (IMPROVE) thermal evolution protocol (Wang et al., 2005). The calculated uncertainties were $\pm 10 \%$ for the measured OC and EC data. The concentrations of other elements (e.g., Al, Cd, Co, Pb, Sb, Zn, K, Ca and Mg) were also measured for 14 of the $\mathrm{PM}_{2.5}$ samples and 16 of the selected potential source materials using ICP-MS or ICP-AES after total acid $\left(\mathrm{HNO}_{3}-\mathrm{HF}-\mathrm{HClO}_{4}\right)$ digestion. A $1.5 \mathrm{~cm}^{2}$ punch from each filter sample and about $0.05 \mathrm{~g}$ of solid material samples were dissolved completely with $\mathrm{HNO}_{3}-\mathrm{HF}-\mathrm{HClO}_{4}$. Note that, due to limited mass of $\mathrm{PM}_{2.5}$ samples, nine $\mathrm{PM}_{2.5}$ samples were exhausted after isotope analysis, and only $14 \mathrm{PM}_{2.5}$ samples were analyzed for the other elements. The soil standard GBW07405 was digested using the same protocol and the measured concentrations of trace elements (TEs, including $\mathrm{Hg}$ ) were consistent with the certified values.

\section{Results}

\subsection{General characteristics of $\mathbf{P M}_{2.5}$}

The contents of $\mathrm{PM}_{2.5}$, OC and EC for the 23 samples are presented in Table S1. The volumetric contents of $\mathrm{PM}_{2.5}$ ranged from 56 to $310 \mu \mathrm{g} \mathrm{m}^{-3}$ (average $120 \pm 61 \mu \mathrm{g} \mathrm{m}^{-3}$ ), and were higher in autumn than the three other seasons (Fig. 1). The $\mathrm{PM}_{2.5}$ samples showed large variations in carbon concentrations, with OC ranged from 2.8 to $42 \mu \mathrm{g} \mathrm{m}^{-3}$ and EC from 1.2 to $9.2 \mu \mathrm{g} \mathrm{m}^{-3}$, averaging $12 \pm 9.6$ and $3.7 \pm 2.3 \mu \mathrm{g} \mathrm{m}^{-3}$, respectively. The $\mathrm{OC}$ and EC contents in autumn (respective mean of $14 \pm 11$ and $4.9 \pm 2.8 \mathrm{\mu g} \mathrm{m}^{-3}$, $n=6$ ) and winter (mean of $19 \pm 13$ and $5.1 \pm 2.3 \mu \mathrm{g} \mathrm{m}^{-3}$, $n=6)$ were approximately doubled compared to those in spring (mean of $7.7 \pm 1.4$ and $2.5 \pm 0.7 \mu \mathrm{g} \mathrm{m}^{-3}, n=6$ ) and summer (mean of $5.9 \pm 1.8$ and $2.0 \pm 0.5 \mu \mathrm{g} \mathrm{m}^{-3}, n=5$ ). Similar seasonal variation was also reported in a previous study (Zhou et al., 2012). When converted to the 


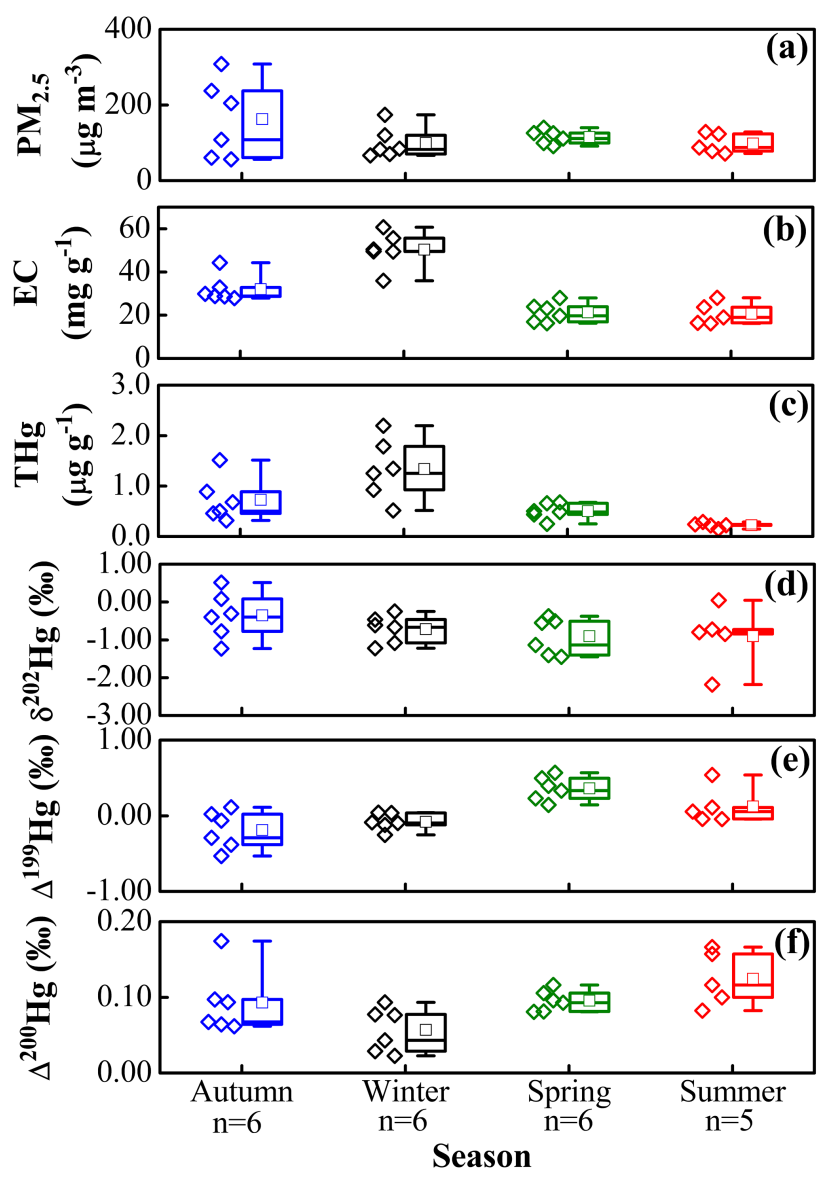

Figure 1. Seasonal variations in $\mathrm{PM}_{2.5}$ (a) and elemental carbon (b) contents, $\mathrm{Hg}$ concentrations (c) and $\mathrm{Hg}$ isotopic ratios (d-f) of the $\mathrm{PM}_{2.5}$ samples. For each box plot, the median is the 50th percentile and error bars extend from the 75 th percentile to the maximum value (upper) and from the 25 th percentile to the minimum value (lower). The small square in each box represents the seasonal mean value.

mass concentrations, the $\mathrm{OC}$ and $\mathrm{EC}$ contents were significantly $(p<0.01)$ higher in winter (mean of $170 \pm 49$ and $50 \pm 8 \mu \mathrm{g} \mathrm{g}^{-1}, n=6$ ) than in other seasons (mean of $71 \pm 18$ and $25 \pm 7.3 \mu \mathrm{g} \mathrm{g}^{-1}, n=17$ ) (Table S1). Since EC contents were closely correlated with OC $\left(r^{2}=0.89, p<0.001\right)$, we discuss only EC contents in the following as an indicator for the source of PM, because EC is a significant pollutant of combustion source that is not readily modified by secondary processes in the atmosphere.

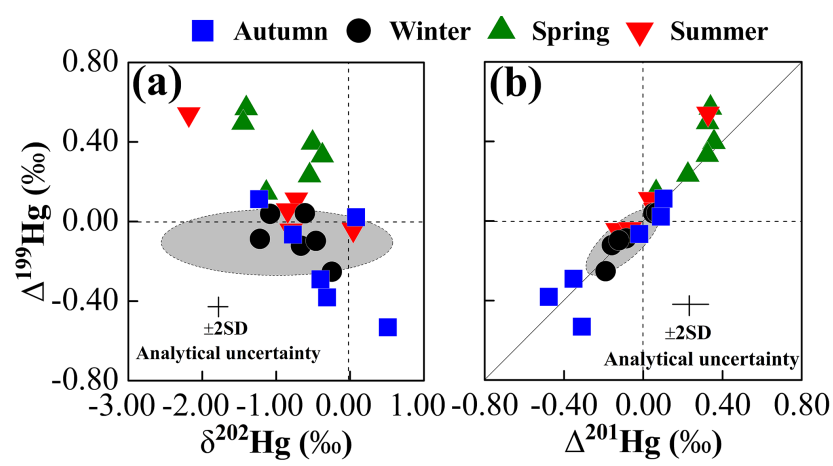

Figure 2. Shown are relationships between $\Delta^{199} \mathrm{Hg}$ and $\delta^{202} \mathrm{Hg}$ (a) and $\Delta^{201} \mathrm{Hg}$ (b) for $23 \mathrm{PM}_{2.5}$ samples. The gray areas are the ranges of $\mathrm{Hg}$ isotope compositions of potential source materials.

\subsection{Seasonal variation in mercury concentration and isotopic composition}

$\mathrm{PM}_{2.5}-\mathrm{Hg}$ volumetric concentrations and isotopic compositions are shown in Table S1. In general, the $\mathrm{PM}_{2.5}$ $\mathrm{Hg}$ concentrations ranged from 11 to $310 \mathrm{pg} \mathrm{m}^{-3}$, with an average value of $90 \pm 80 \mathrm{pg} \mathrm{m}^{-3}$. These values were comparable to those reported at a rural site of Beijing $\left(98 \pm 113 \mathrm{pg} \mathrm{m}^{-3}\right)$ (Zhang et al., 2013b), indoor $\mathrm{PM}_{2.5}$ of Guangzhou (104 $\mathrm{pg} \mathrm{m}^{-3}$ ) (Huang et al., 2012) and several southeastern coastal cities $\left(141 \pm 128 \mathrm{pg} \mathrm{m}^{-3}\right)$ of China (Xu et al., 2013), but they were lower than those reported values for Guiyang $\left(368 \pm 676 \mathrm{pg} \mathrm{m}^{-3}\right)$ of China (Fu et al., 2011). From a global perspective, our $\mathrm{PM}_{2.5-}$ $\mathrm{Hg}$ contents were much higher than those reported for urban areas of other countries such as Seoul in South Korea $\left(23.9 \pm 19.6 \mathrm{pg} \mathrm{m}^{-3}\right)$ (Kim et al., 2009), Gothenburg in Sweden $\left(12.5 \pm 5.9 \mathrm{pg} \mathrm{m}^{-3}\right.$ ) (Li et al., 2008) and Detroit in the USA $\left(20.8 \pm 30.0 \mathrm{pg} \mathrm{m}^{-3}\right)$ (Liu et al., 2007). The averaged $\mathrm{PM}_{2.5}-\mathrm{Hg}$ values showed an evident seasonal variation, with relatively higher value in winter $\left(140 \pm 99 \mathrm{pg} \mathrm{m}^{-3}\right)$ and lower in summer $\left(22 \pm 8.2 \mathrm{pg} \mathrm{m}^{-3}\right.$ ) (see Figs. 1 and 2). Previous studies also reported similar variation for $\mathrm{Hg}$ loads in atmospheric particles in Beijing (Wang et al., 2006; Schleicher et al., 2015); for example, the highest value of $2130 \pm 420 \mathrm{pg} \mathrm{m}^{-3}$ was found in winter 2004, while lower values were generally reported in summer (Wang et al., 2006; Schleicher et al., 2015).

Seasonal variations were also observed for $\mathrm{Hg}$ isotopic compositions (see Figs. 1 and 2 and Table S1). The $\delta^{202} \mathrm{Hg}$ values ranged from -2.18 to $0.51 \%$ (average $-0.71 \pm 0.58 \%$ o $1 \mathrm{SD}, n=23$ ), with the lowest value of $-2.18 \%$ o found on 29 June 2014 (in summer), whereas the highest of $0.51 \%$ was found on 30 September 2013 (in autumn). Interestingly, all samples displayed a large $\Delta^{199} \mathrm{Hg}$ variation from -0.53 to $0.57 \%$ (mean of $0.05 \pm 0.29 \%$ ). Unlike $\delta^{202} \mathrm{Hg}$, the lowest $\Delta^{199} \mathrm{Hg}$ value $(-0.53 \%$ o) was found in autumn (on 30 September 2013), whereas the high- 

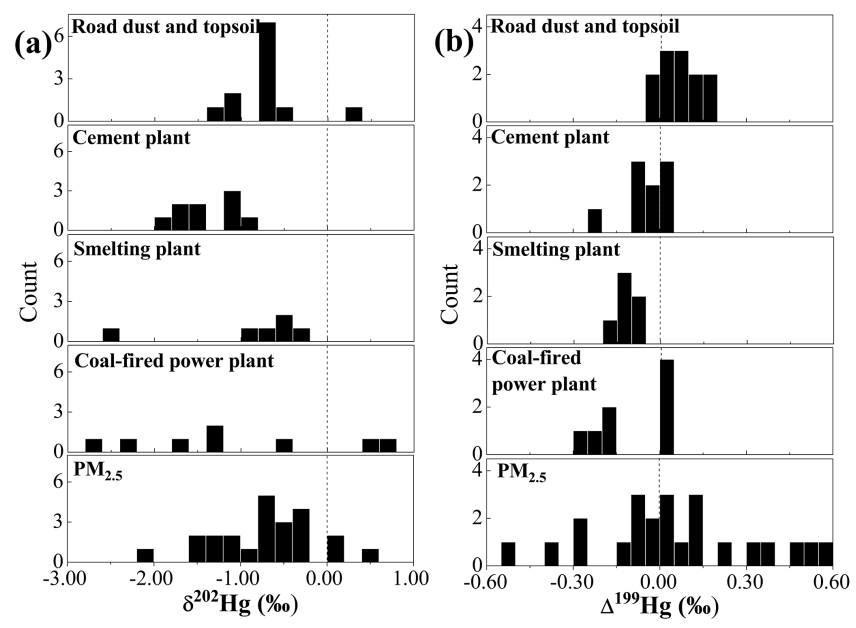

Figure 3. Comparison of isotopic compositions between the selected potential source materials and the $\mathrm{PM}_{2.5}$ samples. The $\delta^{202} \mathrm{Hg}$ values of $\mathrm{PM}_{2.5}-\mathrm{Hg}$ are within the ranges of the source materials, but the $\Delta^{199} \mathrm{Hg}$ values are out of the range, suggesting contribution from other unknown sources or MIF during atmospheric processes.

est value $(0.57 \%$ ) was observed in spring (23 April 2014). Positive even-MIF of $\mathrm{Hg}$ isotope was also determined in all $\mathrm{PM}_{2.5}-\mathrm{Hg}$, with $\Delta^{200} \mathrm{Hg}$ ranging from 0.02 to $0.17 \%$, averaging $0.09 \pm 0.04 \%$ o (Table S1). Three previous studies reported negative $\delta^{202} \mathrm{Hg}$ (from -3.48 to $-0.12 \%$ o) but significantly positive $\Delta^{199} \mathrm{Hg}$ (from -0.31 to $1.36 \%$ ) for atmospheric particles (Rolison et al., 2013; Huang et al., 2015; Das et al., 2016).

\subsection{Mercury content and isotope ratios in potential source materials}

As showed in Table $\mathrm{S} 2$, the $\mathrm{Hg}$ concentrations of the potential source materials ranged widely from 0.35 to $7747 \mathrm{ng} \mathrm{g}^{-1}$, with an exceptionally high value of $10800 \mathrm{ng} \mathrm{g}^{-1}$ for the sintering dust collected by the electrostatic precipitator in a smelting plant. Though the topsoil and road dust samples generally displayed relatively lower $\mathrm{Hg}$ concentrations (e.g., 23 to $408 \mathrm{ng} \mathrm{g}^{-1}$, Table S2), the topsoil collected from Beihai Park in the 2nd ring of Beijing had an exceptionally high $\mathrm{Hg}$ content of $7747 \mathrm{ng} \mathrm{g}^{-1}$. It is worth noting that these data were comparable to the mass-based $\mathrm{Hg}$ concentrations (150 to $2200 \mathrm{ng} \mathrm{g}^{-1}$ with a mean value of $720 \mathrm{ng} \mathrm{g}^{-1}$ ) for the 23 $\mathrm{PM}_{2.5}$ samples (Table $\mathrm{S} 1$ ).

The potential source materials also had a large variation in $\mathrm{Hg}$ isotope compositions (Figs. 2 and 3 and Table S2), with $\delta^{202} \mathrm{Hg}$ ranging from -2.67 to $0.62 \%$ o (average $-0.98 \pm 0.79 \%, 1 \mathrm{SD}, n=30$ ), while $\Delta^{199} \mathrm{Hg}$ ranged from -0.27 to $0.18 \%$ (mean $-0.03 \pm 0.11 \%$ o ) and $\Delta^{200} \mathrm{Hg}$ values ranged from -0.04 to $0.11 \%$ (mean $0.02 \pm 0.04 \%$ ).

\section{Discussion}

Previous studies have demonstrated that coal combustion, cement plant and non-ferrous metal smelting were main sources of $\mathrm{Hg}$ in the atmosphere (Streets et al., 2005; Zhang et al., 2015), respectively contributing about 47, 18.5 and $17.5 \%$ of total anthropogenically emitted $\mathrm{Hg}$ in China(Zhang et al., 2015). In particular, certain events, such as large-scale biomass burning in autumn and excessive coal combustion in the winter heating season, might also have overprinted the concentration of $\mathrm{PM}_{2.5}-\mathrm{Hg}$ and its isotope composition. In addition to the possible direct emission from the above anthropogenic sources, atmospheric processes may have impacted the $\mathrm{PM}_{2.5}-\mathrm{Hg}$ isotopic composition, particularly during the long-range transportation of $\mathrm{PM}_{2.5}-\mathrm{Hg}$ (and thus a long residence time of about a few days to weeks) in the atmosphere (Lin et al., 2007). These potential sources and possible process effects are discussed in the following sections.

\subsection{Evidence for strong anthropogenic contribution}

Anthropogenic emission as the main $\mathrm{PM}_{2.5}-\mathrm{Hg}$ contributing sources is evidenced by the enrichment factor (EF) of $\mathrm{Hg}$ (and other metals), which was a commonly used geochemical indicator for quantifying the enrichment/depletion of a targeted element in environmental samples (Gao et al., 2002; Song et al., 2012; Chen et al., 2014; Mbengue et al., 2014; Lin et al., 2015b). The EF of a given element was calculated using a double normalization (to the less reactive element $\mathrm{Al}$ here) and the upper continental crust (UCC) (Rudnick and Gao, 2003) was chosen as the reference (see details in the Supplement). Al is well adapted to this normalization as it usually has no anthropogenic origin and is not readily modified by secondary processes in the atmosphere, and thus was widely used for enrichment calculation in atmospheric pollution studies (Gao et al., 2002; Waheed et al., 2011; Mbengue et al., 2014; Lin et al., 2015b). The calculated results showed (Table S4) high $\mathrm{EF}(\mathrm{Hg})$ values for the $14 \mathrm{PM}_{2.5}$ samples, ranging from 66 to 424 with an average value of $228 \pm 134$ (1 SD, $n=14$ ), indicating that $\mathrm{PM}_{2.5}-\mathrm{Hg}$ pollution was serious (characterized by significant $\mathrm{Hg}$ enrichment) in Beijing. As it is a TE, $\mathrm{Hg}$ concentration is generally low in natural terrestrial reservoirs (e.g., $50 \mathrm{ppb}$ in UCC) (Rudnick and Gao, 2003). Similar to the UCC, the topsoil was also mainly composed of aluminosilicates with relatively low $\mathrm{Hg}$ concentrations (Table S2). Thus, high $\mathrm{EF}(\mathrm{Hg})$ values probably imply a strong anthropogenic contribution to $\mathrm{Hg}$ in $\mathrm{PM}_{2.5}$. This could be confirmed by very high $\mathrm{EF}(\mathrm{Hg})$ values (up to 226000 , Table S4) determined, for example, in three potential source materials collected from the smelting plant. The high $\mathrm{EF}(\mathrm{Hg})$ values also emphasize the importance of studying toxic metals such as $\mathrm{Hg}$ (and other heavy metals) in atmospheric particles while assessing the potential threat of hazes on human health. 
The strong anthropogenic contribution may be also supported by the relationships between $\mathrm{Hg}$ and other particulate components in $\mathrm{PM}_{2.5}$. Figure $4 \mathrm{a}$ and $\mathrm{b}$ show very good correlations between $\mathrm{PM}_{2.5}-\mathrm{Hg}$ concentration and the volumetric concentrations of $\mathrm{PM}_{2.5}$ and $\mathrm{EC}$, with correlation coefficients $\left(r^{2}\right)$ of 0.40 and 0.80 , respectively. It is well known that atmospheric pollution due to the high concentrations of $\mathrm{PM}_{2.5}$ and EC mainly results from anthropogenic emissions (Gao et al., 2015; Lin et al., 2015b). $\mathrm{PM}_{2.5}-\mathrm{Hg}$ also displayed linear relationships with trace metals. Figure $4 \mathrm{c}$ and d show the examples with $\mathrm{Co}$ and $\mathrm{Zn}\left(r^{2}\right.$ of 0.74 and 0.44 , respectively, $p<0.01)$. High metal contents in atmospheric particles are generally related to human activities. For example, combustion and smelting release large amount of TEs into the atmosphere (Xu et al., 2004; Nzihou and Stanmore, 2013). The fact that all $\mathrm{PM}_{2.5}$ samples displayed very high EFs for "anthropophile" elements (elements were generally enriched by human activities) (Chen et al., 2014) such as $\mathrm{Cd}, \mathrm{Cu}, \mathrm{Pb}, \mathrm{Sb}$, $\mathrm{Se}, \mathrm{Tl}$ and $\mathrm{Zn}$ (ranging from 10 to 20869 , Table S4) clearly illustrated the anthropogenic contribution to these elements in $\mathrm{PM}_{2.5}$. As a result, fine atmospheric particles in Beijing were strongly enriched in $\mathrm{Hg}$ and other TEs, which was likely caused by elevated anthropogenic activities.

\subsection{Isotopic overprint of potential anthropogenic $\mathbf{H g}$ sources}

$\mathrm{Hg}$ isotopic signatures may further indicate that human activities contributed to a large proportion of $\mathrm{PM}_{2.5}-\mathrm{Hg}$. In this study, all samples displayed a large variation in $\delta^{202} \mathrm{Hg}$ (from -2.18 to $0.51 \%$, Table S1), similar to those values (from -2.67 to $0.62 \%$, Table S2) determined for the particulate materials from potential sources such as coal combustion (average $-1.10 \pm 1.20 \%$, $1 \mathrm{SD}, n=8$ ), smelting $(-0.87 \pm 0.82 \%, 1 \mathrm{SD}, n=6)$ and cement plants $(-1.42 \pm 0.36 \%$ o, $1 \mathrm{SD}, n=10)$, as demonstrated in Figs. 2 and 3 . This similarity might indicate the emission of these anthropogenic sources as the possible contributing sources of $\mathrm{PM}_{2.5}-\mathrm{Hg}$. Though the anthropogenic samples collected in this study could not cover the whole spectrum of anthropogenic contributions, previous studies reported a similar $\delta^{202} \mathrm{Hg}$ range (from -3.48 to $0.77 \%$ ) for potential source materials worldwide (Biswas et al., 2008; Estrade et al., 2011; Sun et al., 2013, 2014; Yin et al., 2014; Wang et al., 2015b; Das et al., 2016). In fact, most $\mathrm{PM}_{2.5}$ samples possessed $\Delta^{199} \mathrm{Hg}$ similar to those determined in abovementioned particulate materials $(-0.27$ to $0.04 \%$, Figs. 2 and 3 ) in this study, suggesting these anthropogenic emission as the major sources of $\mathrm{PM}_{2.5}-\mathrm{Hg}$.

Interestingly, $\mathrm{Hg}$ isotope compositions were correlated well with the elements such as $\mathrm{Co}, \mathrm{Ni}$ and $\mathrm{Sb}$ (here the mass ratio of a particular element to aluminum was used to cancel out the dilution effect by major mineral phase), as shown in Fig. 5a and $\mathrm{b}$ for the example of Co. These correlations might indicate that $\mathrm{Hg}$ and some other metals had common prove-
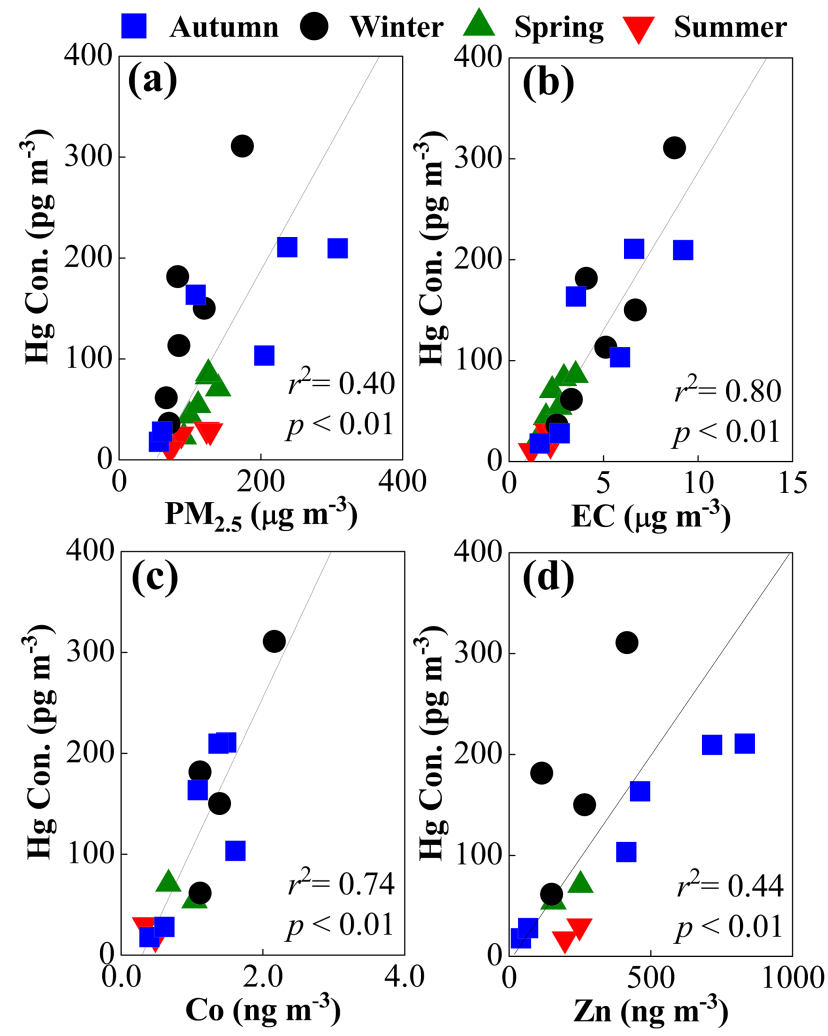

Figure 4. Plots of the volumetric $\mathrm{Hg}$ concentration versus $\mathrm{PM}_{2.5}$ content (a), EC content (b), and concentrations of Co (c) and $\mathrm{Zn}$ (d) for the $\mathrm{PM}_{2.5}$ samples. In both (c) and (d), only $14 \mathrm{PM}_{2.5}$ samples are shown with $\mathrm{Co}$ and $\mathrm{Zn}$ data sets, because $9 \mathrm{PM}_{2.5}$ samples were exhausted after isotope and OC / EC analyses, and only those $14 \mathrm{PM}_{2.5}$ samples were analyzed for the other elements.

nance, likely from anthropogenic combustion, as discussed above. A careful investigation of the correlations amongst metal elements, along with $\mathrm{Hg}$ isotopic data, further indicated anthropogenic source category. The principal component analysis (PCA) of $\mathrm{Hg}$ and other TEs (see Table S5) demonstrated that likely four factors might control the variance of the entire data set over four seasons. In accordance with the above discussion, these four factors were likely a mixture of coal combustion and nonferrous metal smelting (characterized by high contents of $\mathrm{Pb}, \mathrm{Rb}, \mathrm{Se}, \mathrm{Zn}, \mathrm{Tl}, \mathrm{Cr}$ and $\mathrm{Cd}$ ), cement production (enriched in $\mathrm{Ca}, \mathrm{Sr}, \mathrm{Al}$ and $\mathrm{Mg}$ ), traffic emission and biomass burning, with their contributions estimated to be about 39, 24, 23, and $7 \%$ (Table S5).

As a result, the $\mathrm{Hg}$ isotopic compositions may potentially suggest that coal combustion, smelting and cement plants were major sources of $\mathrm{PM}_{2.5}-\mathrm{Hg}$. The higher $\mathrm{EF}(\mathrm{Hg})$ values and the detail investigation of elemental data supported this hypothesis. However, without careful characterization of potential sources, we are unable to quantify the contribution from each source at this stage. It is worth noting that Fig. 6a and b show that $\delta^{202} \mathrm{Hg}$ increased with $\mathrm{EF}(\mathrm{Hg})\left(r^{2}=0.55\right)$, 


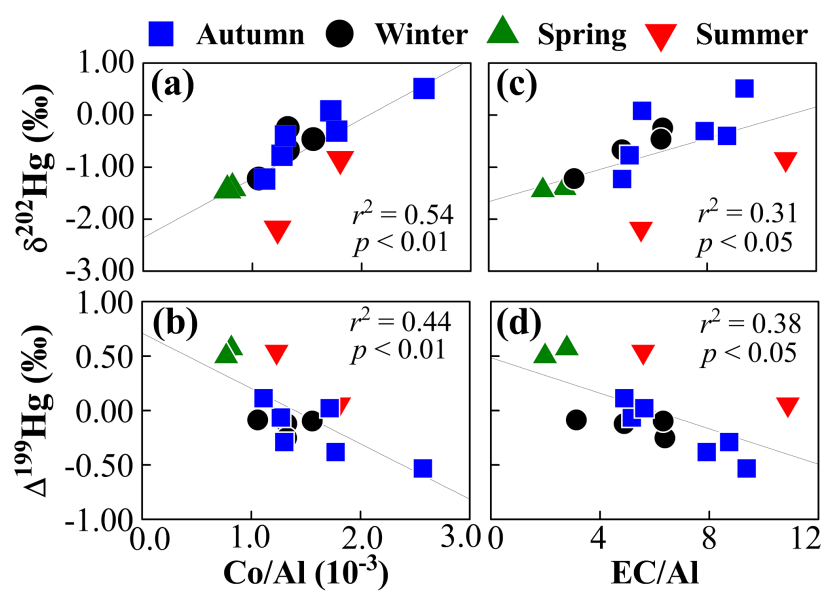

Figure 5. Correlations between $\mathrm{Hg}$ isotopic composition $\left(\delta^{202} \mathrm{Hg}\right.$ and $\left.\Delta^{199} \mathrm{Hg}\right)$ and $\mathrm{Co} / \mathrm{Al}(\mathbf{a}, \mathbf{b})$ and $\mathrm{EC} / \mathrm{Al}(\mathbf{c}, \mathbf{d})$ elemental mass ratios. In all cases, $\delta^{202} \mathrm{Hg}$ values are positively, and $\Delta^{199} \mathrm{Hg}$ values negatively, correlated with the $\mathrm{Co} / \mathrm{Al}$ and $\mathrm{EC} / \mathrm{Al}$ ratios.

whereas $\Delta^{199} \mathrm{Hg}$ decreased with $\mathrm{EF}(\mathrm{Hg})\left(r^{2}=0.36\right)$. These correlations may suggest that the large isotope variation in $\mathrm{PM}_{2.5}-\mathrm{Hg}$ might be mainly controlled by two end members with contrasting $\delta^{202} \mathrm{Hg}$ and $\Delta^{199} \mathrm{Hg}$. The end $\Delta^{199} \mathrm{Hg}$ values of correlations, however, could not be explained by the above-defined anthropogenic sources, which generally had insignificant odd-MIF. The contribution from additional sources or possible processes was thus needed to explain the extreme $\Delta^{199} \mathrm{Hg}$ values. Accordingly, the $\delta^{202} \mathrm{Hg}$ and $\Delta^{199} \mathrm{Hg}$ exhibited contrast relationships with the $\mathrm{EC} / \mathrm{Al}$ ratios (Fig. 5c and d). As relatively higher EC contents were generally derived from coal combustion and biomass burning (Zhang et al., 2008; Saleh et al., 2014), these two non-point emission sources might account for the $\Delta^{199} \mathrm{Hg}$ end values.

\subsection{Dominant contribution from coal combustion in winter}

High EC content in winter $\mathrm{PM}_{2.5}$ might result from additional coal combustion during the heating season, when coal was widely used in both suburban communities and rural individual families (Wang et al., 2006; Song et al., 2007; Schleicher et al., 2015). This additional coal burning could considerably increase $\mathrm{Hg}$ and EC emission, explaining the relatively higher $\mathrm{PM}_{2.5}-\mathrm{Hg}\left(1340 \mathrm{ng} \mathrm{g}^{-1}, p<0.01\right)$ and carbon contents (Table S1). In this study, both $\delta^{202} \mathrm{Hg}$ (mean $-0.71 \pm 0.37 \%$ ) and $\Delta^{199} \mathrm{Hg} \quad(-0.08 \pm 0.11 \%$, $1 \mathrm{SD}, n=6$ ) values for winter $\mathrm{PM}_{2.5}$ samples were consistent with those in coal (average $\delta^{202} \mathrm{Hg}$ values of $-0.73 \pm 0.33 \%$ o and $\Delta^{199} \mathrm{Hg}$ of $-0.02 \pm 0.08 \%$ ) from northeastern China (Yin et al., 2014), possibly supporting the above conclusion. In addition to EC contents, the $\mathrm{Zn} / \mathrm{Al}$ ratio may provide information for PM from industrial (e.g., metal smelting) emission sources. In the Zn / Al vs. EC diagram (Fig. 7), all win-

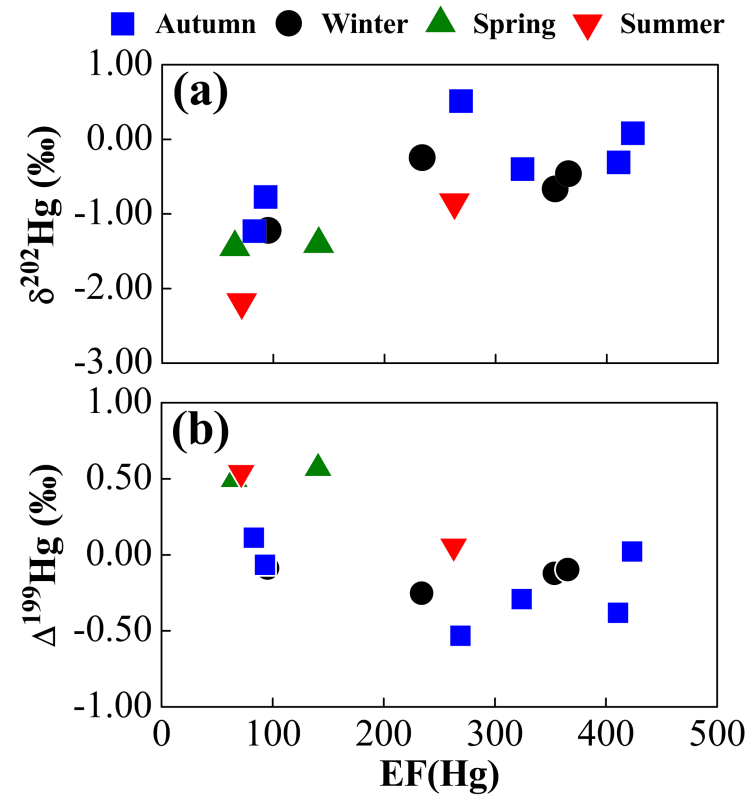

Figure 6. Correlations between $\mathrm{Hg}$ isotopic composition $\left(\delta^{202} \mathrm{Hg}\right.$ and $\left.\Delta^{199} \mathrm{Hg}\right)$ and $\mathrm{Hg}$ enrichment factor $\mathrm{EF}(\mathrm{Hg})(\mathbf{a}, \mathbf{b})$. The $\delta^{202} \mathrm{Hg}$ value is positively correlated with the $\mathrm{EF}(\mathrm{Hg})$, while the $\Delta^{199} \mathrm{Hg}$ value is negatively correlated with the $\mathrm{EF}(\mathrm{Hg})$.

ter samples displayed a linear relationship $\left(r^{2}=0.94\right)$ different from the samples of other seasons. Compared to the data of other seasons, the volumetric EC concentrations varied greatly in winter, whereas the $\mathrm{Zn} / \mathrm{Al}$ ratio of the same season remained stable. This variation may be derived from the emission of coal burning, which is characterized by high carbon content but relatively low $\mathrm{Zn}$ concentration (Nzihou and Stanmore, 2013; Saleh et al., 2014). This again highlights the dominant contribution from coal combustion. The backward trajectory calculated by the Hybrid Single Particle Lagrangian Integrated Trajectory (HYSPLIT) model (Fig. S1 in the Supplement) showed the dominant northwestern wind in winter. In this case, the fact that the transported air masses were derived from the background region (less populated and underdeveloped) could potentially explain both the lower volume-based concentrations of $\mathrm{Hg}$, TEs (e.g., $\mathrm{Zn}$ ) and EC (Fig. 7) and the higher mass-based contents of Hg, TEs (e.g., $\mathrm{Zn})$ and EC (Table S1 in the Supplement) in some winter samples. The dilution by this background air could also explain the comparable EC content in winter and autumn (Figs. 1 and 7).

\subsection{Important biomass burning input in autumn}

Biomass burning that often occurred in northern China might be the cause of relatively higher EC volumetric concentrations in autumn $\mathrm{PM}_{2.5}$. The HYSPLIT model (Fig. S2) showed that, unlike the winter $\mathrm{PM}_{2.5}$, the samples collected in autumn were strongly impacted by northward wind. 


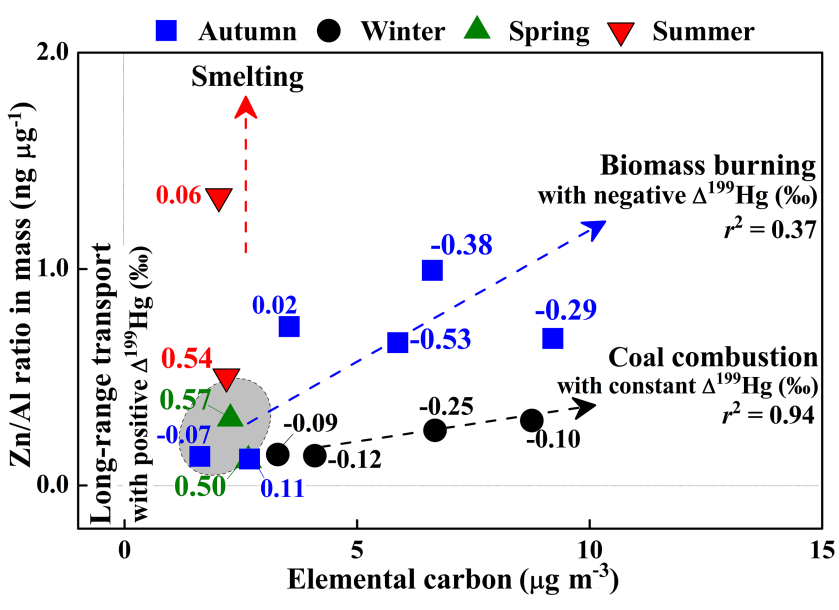

Figure 7. Correlations between $\mathrm{Zn} / \mathrm{Al}$ ratios and EC contents suggest seasonal characteristics of $\mathrm{PM}_{2.5}$ sources with seasonally unique $\Delta^{199} \mathrm{Hg}$ signatures (in \%o).

Biomass burning that occurred in the south of Beijing during the autumn harvesting season could transport a large amount of $\mathrm{EC}$ (and $\mathrm{Hg}$ ) to Beijing, adding a potential source to $\mathrm{PM}_{2.5}-\mathrm{Hg}$. Though biomass burning is not an important source in an annual time scale (from PCA estimation), it may display major contribution in a short time period in autumn. Previous studies showed that this source might account for 20 to $60 \%$ of $\mathrm{PM}_{2.5}$ in Beijing during peak days of biomass burning (Zheng et al., 2005a, b). Isotopically, $\mathrm{PM}_{2.5}$ collected in the arriving air masses from south was characterized by significantly negative $\Delta^{199} \mathrm{Hg}$ values (from -0.54 to $-0.29 \%$ ), whereas samples collected in the northwestern wind event exhibited $\Delta^{199} \mathrm{Hg}$ values close to zero or slightly positive, indicating a negative $\Delta^{199} \mathrm{Hg}$ signature in biomass burning emission $\mathrm{Hg}$. Our newly obtained data on $\mathrm{Hg}$ isotopes from biomass burning showed negative $\Delta^{199} \mathrm{Hg}$ (which will be published in the future), supporting our hypothesis. Moreover, prior studies have generally reported negative $\Delta^{199} \mathrm{Hg}$ values for biological samples including foliage (about $-0.37 \%$ ), rice stem (about $-0.37 \%$ ) and litter (about $-0.44 \%$ ) (Demers et al., 2013; Yin et al., 2013; Jiskra et al., 2015), even down to $-1.00 \%$ o for some lichen (Carignan et al., 2009). The odd-MIF signature may be conserved during complete biomass burning as this process would not produce any mass-independent fractionation (Sun et al., 2014; Huang et al., 2015).

Interestingly, the autumn $\mathrm{PM}_{2.5}$ had a $\mathrm{Zn} / \mathrm{Al}$ versus EC correlation $\left(r^{2}=0.37\right)$ distinctly different from the winter samples, as well as from spring and summer samples (Fig. 7). This difference may imply another carbon-enriched contribution in autumn other than coal combustion. In fact, the high occurrence of biomass burning in the south (Hebei and Henan provinces) may lead to the EC content (volumebased) increasing in autumn air mass. Thus, the high EC air mass input from biomass burning could explain the dif- ferent trend which defined by autumn $\mathrm{PM}_{2.5}$, while the above-discussed contribution from industries (mainly smelting) could explain the higher $\mathrm{Zn}$ (at a given EC content) in summer samples. Though most samples with high EC could result from biomass burning, two autumn samples displaying relatively low EC could be caused by the dilution from northern background air mass (Fig. S2), as demonstrated by the HYSPLIT model.

\subsection{Contribution from long-range-transported $\mathrm{PM}_{2.5}$-Hg}

Besides the dominant contribution from local or regional emissions, long-range-transported $\mathrm{Hg}$ might impact on $\mathrm{PM}_{2.5}$-Hg in Beijing (Han et al., 2015; Wang et al., 2015a). As shown in Figs. 1 and 2 and Table S1, the six spring PM $_{2.5}$ samples and the one early summer sample had much high $\Delta^{199} \mathrm{Hg}$ (from 0.14 to $0.57 \%$, mean of $0.39 \pm 0.16 \%$, $1 \mathrm{SD}$, $n=7$ ) and $\Delta^{200} \mathrm{Hg}$ values (from 0.08 to $0.12 \%$, mean of $0.10 \pm 0.01 \%, 1 \mathrm{SD}, n=7)$. These high values could not be explained by the above-defined anthropogenic contributors having generally negative or close to zero MIF (Figs. 2 and 3), yet another contribution or fractionation during atmospheric processing is needed to explain all data sets. The long-range-transported $\mathrm{PM}_{2.5}$ may be such contributor in addition to the direct local or regional anthropogenic emission (Han et al., 2015; Wang et al., 2015a).

The HYSPLIT calculation showed that the arriving air masses of these samples generally came from a long distance (mainly from the north and northwest, Figs. S3 and S4), suggesting a contribution of long-range transportation, given the residence time of $\mathrm{PM}_{2.5}-\mathrm{Hg}$ (days to weeks) (Lin et al., 2007). Unfortunately, we were not able to collect and analyze the typical long-range-transported $\mathrm{Hg}$ in this study. Previous studies have reported that long-range-transported $\mathrm{Hg}$ might exhibit relatively higher $\Delta^{199} \mathrm{Hg}$ (up to $1.16 \%$ o) due to the extensive photolysis reaction (Chen et al., 2012; Wang et al., 2015b; Yuan et al., 2015). In fact, the samples with significantly positive $\Delta^{199} \mathrm{Hg}$ were collected during a period (at least 3 days before sampling) with long daily sunshine $(>8.8 \mathrm{~h}$ ) for Beijing and adjacent regions (Table S1). Such climate conditions might be favorable for photoreduction of atmospheric $\mathrm{Hg}^{2+}$, which preferentially enriches odd isotopes in solution or aerosols. The fact that the background TSP sample from the Yanqing region had higher $\Delta^{199} \mathrm{Hg}$ $\left(0.18 \%\right.$ o, Table S2) than $\mathrm{PM}_{2.5}$ samples collected at the same time in the center of Beijing might suggest higher odd-MIF values for long-range-transported $\mathrm{Hg}$, since the local $\mathrm{Hg}$ emission is very limited in this rural area. Moreover, the higher $\Delta^{200} \mathrm{Hg}$ values (from 0.08 to $0.12 \%$ o, Table S1) determined in these samples may also indicate the contribution of long-range transportation, since even-MIF was thought to be a conservative indicator of upper atmosphere chemistry (Chen et al., 2012; Cai and Chen, 2016). Since the locally emitted $\mathrm{PM}_{2.5}-\mathrm{Hg}$ (having lower or close to zero $\Delta^{199} \mathrm{Hg}$ 
and $\Delta^{200} \mathrm{Hg}$ ) mainly resided and accumulated in the atmospheric boundary layer (generally $<1000 \mathrm{~m}$ ), and thus could be largely scavenged by precipitation (Yuan et al., 2015), the higher $\Delta^{199} \mathrm{Hg}$ values (from 0.06 to $0.14 \%$; see Table S1) for $\mathrm{PM}_{2.5}$ sampled after precipitation event supported the contribution of long-range transport to $\mathrm{PM}_{2.5}-\mathrm{Hg}$. Finally, as the background $\mathrm{PM}_{2.5}$ with little input from anthropogenic activities is likely characterized by low contents of trace metals (such as Zn) and organic matter (Song et al., 2007; Zhou et al., 2012), the long-range transport contribution could also explain $\mathrm{PM}_{2.5}$ samples with relatively low EC content and $\mathrm{Zn} / \mathrm{Al}$ ratio in Fig. 7.

\subsection{Possible process effects on transported $\mathrm{PM}_{2.5}-\mathrm{Hg}$}

The atmospheric processes such as secondary aerosol production, adsorption (and desorption) and redox reactions may induce a redistribution of $\mathrm{Hg}$ among GEM, RGM and $\mathrm{PBM}$ and simultaneously fractionate $\mathrm{Hg}$ isotopes in $\mathrm{PM}_{2.5}$, possibly resulting in a difference of $\mathrm{Hg}$ isotopic composition between $\mathrm{PM}_{2.5}$ and source materials. Up to now, $\mathrm{Hg}$ isotopic fractionation has rarely been reported for $\mathrm{Hg}$ redistribution and secondary aerosol formation in the atmosphere. However, the fact that the contents of secondary organic carbon (see detailed calculation in the Supplement) had no correlation $\left(r^{2}<0.09, p>0.18\right)$ with either $\delta^{202} \mathrm{Hg}$ or $\Delta^{199} \mathrm{Hg}$ may imply a limited effect of such processes. Previous studies have showed limited adsorption of $\mathrm{Hg}^{0}$ on atmospheric particles (Seigneur et al., 1998). More importantly, according to the experiments conducted under aqueous conditions, the adsorption/desorption and precipitation of $\mathrm{Hg}^{2+}$ may only induce very small MIF of Hg isotopes (Jiskra et al., 2012; Smith et al., 2015), in contrast with our observation. Therefore, the effect of adsorption or precipitation was probably limited to MIF of $\mathrm{Hg}$ isotopes in $\mathrm{PM}_{2.5}$. In this study, all $23 \mathrm{PM}_{2.5}$ samples defined a straight line in Fig. 2 with a $\Delta^{199} \mathrm{Hg} / \Delta^{201} \mathrm{Hg}$ slope of about 1.1 , consistent with the results of the $\mathrm{Hg}^{2+}$ photoreduction experiment (Bergquist and Blum, 2007; Zheng and Hintelmann, 2009), suggesting a possible effect of photochemical reduction during $\mathrm{PM}_{2.5}-\mathrm{Hg}$ transport. Potentially, the enrichment of odd isotopes in reactants (here particles) during these processes can explain the positive $\Delta^{199} \mathrm{Hg}$ in spring and summer samples. However, most samples collected in autumn and winter displayed significant negative $\Delta^{199} \mathrm{Hg}$ values (down to $-0.54 \%$, Figs. 1 , 2, 4 and 5, and Table S1). Therefore, the photoreduction of divalent $\mathrm{Hg}$ species cannot explain the total variation in $\mathrm{Hg}$ isotope ratios determined in all samples, especially the oddMIF. Moreover, the inverse relationship $\left(r^{2}=0.45, p<0.01\right)$ between $\Delta^{199} \mathrm{Hg}$ and $\delta^{202} \mathrm{Hg}$ was inconsistent with the experimental results of photoreduction that generally showed positive correlation for the residual $\mathrm{Hg}$ pool (here particles) (Bergquist and Blum, 2007; Zheng and Hintelmann, 2009). All these arguments suggest that these processes may not be the major mechanism to produce large, even contrasting,
$\mathrm{Hg}$ isotope variation in $\mathrm{Hg}$-enriched fine atmospheric particles. A recent study reported $\mathrm{Hg}$, isotopic fractionation during $\mathrm{Hg}^{0}$ oxidation showed a positive relationship between $\Delta^{199} \mathrm{Hg}$ and $\delta^{202} \mathrm{Hg}$ for $\mathrm{Cl}$-initiated oxidation but a negative relationship for Br-initiated oxidation. Though our $\mathrm{PM}_{2.5}$ samples also displayed a decrease in $\Delta^{199} \mathrm{Hg}$ with $\delta^{202} \mathrm{Hg}$ (Fig. 2), similar to the Br-initiated oxidation, they had a $\Delta^{199} \mathrm{Hg} / \Delta^{201} \mathrm{Hg}$ ratio (1.1) lower than that $(1.6 \pm 0.3)$ of Br-initiated oxidation, and much lower than that (1.9 \pm 0.2$)$ of Cl-initiated oxidation (Sun et al., 2016). Though we cannot exclude the contribution of $\mathrm{Hg}^{0}$ oxidation to $\mathrm{PM}_{2.5}$ $\mathrm{Hg}$, given the fact that halogen-initiated oxidation would not largely occur in in-land atmospheric boundary layer, oxidation would not be a dominant controlling factor causing the seasonal variation in $\mathrm{Hg}$ isotopes in $\mathrm{PM}_{2.5}$ particles. We thus suggest that the contributions from different sources may be the better scenario to explain the seasonal variation in $\mathrm{Hg}$ isotopic compositions we measured for the $\mathrm{PM}_{2.5}$ samples.

\section{Conclusions}

In summary, our study reported, for the first time, large range and seasonal variations in both MDF and MIF of $\mathrm{Hg}$ isotopes in haze particulate $\left(\mathrm{PM}_{2.5}\right)$ samples collected from Beijing. The strong anthropogenic input to $\mathrm{PM}_{2.5}-\mathrm{Hg}$ was evidenced by the high enrichment of $\mathrm{Hg}$ (and other "anthropophile" elements) and $\mathrm{Hg}$ isotopic compositions. Our data showed that mixing of variable contributing sources likely triggered the seasonal variation in $\mathrm{Hg}$ isotopic ratio. Major potential contributing sources were identified by coupling $\mathrm{Hg}$ isotope data with other geochemical parameters (e.g., $\mathrm{PM}_{2.5}$, EC, element concentrations) and meteorological data and showed variable contribution in four seasons, with continuous industrial input (e.g., smelting, cement production and coal combustion) over the year and predominant contributions from coal combustion and biomass burning in winter and autumn, respectively. In addition to the local and/or regional emissions, long-range-transported $\mathrm{Hg}$ was probably also a contributor to $\mathrm{PM}_{2.5}-\mathrm{Hg}$, accounting for the relatively higher odd-MIF particularly found in spring and early summer. This study demonstrated the potential use of isotopes for tracing the sources of heavy metals and their vectors in the atmosphere, and stressed the importance of studying toxic metals such as $\mathrm{Hg}$ (and other heavy metals) in atmospheric particles while assessing the potential threat of hazes on human health.

\section{The Supplement related to this article is available online at doi:10.5194/acp-16-11773-2016-supplement.}

Acknowledgements. We thank J. G. Wiederhold of the University of Vienna and the two anonymous reviewers for their 
constructive comments and suggestions. This study was financially supported by the National "973" Program (no. 2013CB430001), the "Strategic Priority Research Program" (no. XDB05030302 and XDB05030304), the Natural Science Foundation of China (no. 41273023, U1301231, 41561134017, 41173024) and the "Hundred Talents" project of the Chinese Academy of Sciences. Q. Huang also thanks the China Postdoctoral Science Foundation (no. 2014M550472).

Edited by: L. Zhang

Reviewed by: J. G. Wiederhold and two anonymous referees

\section{References}

Bergquist, B. A. and Blum, J. D.: Mass-dependent and -independent fractionation of $\mathrm{Hg}$ isotopes by photoreduction in aquatic systems, Science, 318, 417-420, 2007.

Biswas, A., Blum, J. D., Bergquist, B. A., Keeler, G. J., and Xie, Z. Q.: Natural mercury isotope variation in coal deposits and organic soils, Environ. Sci. Technol., 42, 8303-8309, 2008.

Blum, J. D. and Bergquist, B. A.: Reporting of variations in the natural isotopic composition of mercury, Anal. Bioanal. Chem., 388, 353-359, 2007.

Blum, J. D., Sherman, L. S., and Johnson, M. W.: Mercury isotopes in earth and environmental sciences, Annu. Revi. Earth Pl. Sc., 42, 249-269, 2014.

Buchachenko, A. L.: Mercury isotope effects in the environmental chemistry and biochemistry of mercury-containing compounds, Russ. Chem. Rev., 78, 319-328, 2009.

Cai, H. and Chen, J.: Mass-independent fractionation of even mercury isotopes, Sci. Bull., 61, 116-124, 2016.

Carignan, J., Estrade, N., Sonke, J. E., and Donard, O. F. X.: Odd isotope deficits in atmospheric $\mathrm{Hg}$ measured in Lichens, Environ. Sci. Technol., 43, 5660-5664, 2009.

Chen, J. B., Hintelmann, H., and Dimock, B.: Chromatographic preconcentration of $\mathrm{Hg}$ from dilute aqueous solutions for isotopic measurement by MC-ICP-MS, J. Anal. At. Spectrom., 25, 1402 1409, 2010.

Chen, J. B., Hintelmann, H., Feng, X. B., and Dimock, B.: Unusual fractionation of both odd and even mercury isotopes in precipitation from Peterborough, ON, Canada, Geochim. Cosmochim. Acta, 90, 33-46, 2012.

Chen, J. B., Gaillardet, J., Bouchez, J., Louvat, P., and Wang, Y. N.: Anthropophile elements in river sediments: Overview from the Seine River, France, Geochem. Geophys. Geosys., 15, 45264546, 2014.

Das, R., Wang, X., Khezri, B., Webster, R. D., Sikdar, P. K., and Datta, S.: Mercury isotopes of atmospheric particle bound mercury for source apportionment study in urban Kolkata, India, Elementa, 4, 000098, doi:10.12952/journal.elementa.000098, 2016.

Demers, J. D., Blum, J. D., and Zak, D. R.: Mercury isotopes in a forested ecosystem: Implications for air-surface exchange dynamics and the global mercury cycle, Global Biogeochem. Cy., 27, 222-238, 2013.

Demers, J. D., Sherman, L. S., Blum, J. D., Marsik, F. J., and Dvonch, J. T.: Coupling atmospheric mercury isotope ratios and meteorology to identify sources of mercury impacting a coastal urban-region near Pensacola, Florida, USA, Global Biogeochem. Cy., 29, 1689-1705, 2015a.

Demers, J. D., Sherman, L. S., Blum, J. D., Marsik, F. J., and Dvonch, J. T.: Coupling atmospheric mercury isotope ratios and meteorology to identify sources of mercury impacting a coastal urban-industrial region near Pensacola, Florida, USA, Global Biogeochem. Cy., 29, 1689-1705, 2015 b.

Eiler, J. M., Bergquist, B., Bourg, I., Cartigny, P., Farquhar, J., Gagnon, A., Guo, W., Halevy, I., Hofmann, A., Larson, T. E., Levin, N., Schauble, E. A., and Stolper, D.: Frontiers of stable isotope geoscience, Chem. Geol., 372, 119-143, 2014.

Enrico, M., Roux, G. L., Marusczak, N., Heimbürger, L.-E., Claustres, A., Fu, X., Sun, R., and Sonke, J. E.: Atmospheric Mercury Transfer to Peat Bogs Dominated by Gaseous Elemental Mercury Dry Deposition, Environ. Sci. Technol., 50, 2405-2412, 2016.

Estrade, N., Carignan, J., and Donard, O. F. X.: Tracing and quantifying anthropogenic mercury sources in soils of northern France using isotopic signatures, Environ. Sci. Technol., 45, 1235-1242, 2011.

Feng, X. B., Foucher, D., Hintelmann, H., Yan, H. Y., He, T. R., and Qiu, G. L.: Tracing mercury contamination sources in sediments using mercury isotope compositions, Environ. Sci. Technol., 44, 3363-3368, 2010.

Fu, X., Marusczak, N., Wang, X., Gheusi, F., and Sonke, J. E.: Isotopic Composition of Gaseous Elemental Mercury in the Free Troposphere of the Pic du Midi Observatory, France, Environ. Sci. Technol., 50, 5641-5650, 2016.

Fu, X. W., Feng, X. B., Zhu, W. Z., Zheng, W., Wang, S. F., and Lu, J. Y.: Total particulate and reactive gaseous mercury in ambient air on the eastern slope of the Mt. Gongga area, China, Appl. Geochem., 23, 408-418, 2008.

Fu, X. W., Feng, X. B., Qiu, G. L., Shang, L. H., and Zhang, H.: Speciated atmospheric mercury and its potential source in Guiyang, China, Atmos. Environ., 45, 4205-4212, 2011.

Fu, X. W., Feng, X. B., Sommar, J., and Wang, S. F.: A review of studies on atmospheric mercury in China, Sci. Total Environ., 421, 73-81, 2012.

Fu, X. W., Heimburger, L. E., and Sonke, J. E.: Collection of atmospheric gaseous mercury for stable isotope analysis using iodineand chlorine-impregnated activated carbon traps, J. Anal. At. Spectrom., 29, 841-852, 2014.

Gao, J., Tian, H., Cheng, K., Lu, L., Zheng, M., Wang, S., Hao, J., Wang, K., Hua, S., Zhu, C., and Wang, Y.: The variation of chemical characteristics of $\mathrm{PM}_{2.5}$ and $\mathrm{PM}_{10}$ and formation causes during two haze pollution events in urban Beijing, China, Atmos. Environ., 107, 1-8, doi:10.1016/j.atmosenv.2015.02.022, 2015.

Gao, Y., Nelson, E. D., Field, M. P., Ding, Q., Li, H., Sherrell, R. M., Gigliotti, C. L., Van Ry, D. A., Glenn, T. R., and Eisenreich, S. J.: Characterization of atmospheric trace elements on $\mathrm{PM}_{2.5}$ particulate matter over the New York-New Jersey harbor estuary, Atmos. Environ., 36, 1077-1086, 2002.

Ghosh, S., Schauble, E. A., Lacrampe Couloume, G., Blum, J. D., and Bergquist, B. A.: Estimation of nuclear volume dependent fractionation of mercury isotopes in equilibrium liquid-vapor evaporation experiments, Chem. Geol., 336, 5-12, 2013.

Gratz, L. E., Keeler, G. J., Blum, J. D., and Sherman, L. S.: Isotopic composition and fractionation of mercury in Great Lakes precipitation and ambient air, Environ. Sci. Technol., 44, 7764-7770, 2010 . 
Han, L., Cheng, S., Zhuang, G., Ning, H., Wang, H., Wei, W., and Zhao, X.: The changes and long-range transport of $\mathrm{PM}_{2.5}$ in Beijing in the past decade, Atmos. Environ., 110, 186-195, 2015.

Hintelmann, H. and Lu, S. Y.: High precision isotope ratio measurements of mercury isotopes in cinnabar ores using multi-collector inductively coupled plasma mass spectrometry, Analyst, 128, 635-639, 2003.

Hintelmann, H. and Zheng, W.: Tracking geochemical transformations and transport of mercury through isotope fractionation, in: Environmental Chemistry and Toxicology of Mercury, John Wiley \& Sons New York, 293-327, 2012.

Huang, M. J., Wang, W., Leung, H. M., Chan, C. Y., Liu, W. K., Wong, M. H., and Cheung, K. C.: Mercury levels in road dust and household TSP/PM 2.5 related to concentrations in hair in Guangzhou, China, Ecotox. Environ. Safe, 81, 27-35, 2012.

Huang, Q., Liu, Y. L., Chen, J. B., Feng, X. B., Huang, W. L., Yuan, S. L., Cai, H. M., and Fu, X. W.: An improved dual-stage protocol to pre-concentrate mercury from airborne particles for precise isotopic measurement, J. Anal. Atom. Spectrom., 30, 957-966, 2015.

Huang, R.-J., Zhang, Y., Bozzetti, C., Ho, K.-F., Cao, J.-J., Han, Y., Daellenbach, K. R., Slowik, J. G., Platt, S. M., and Canonaco, F.: High secondary aerosol contribution to particulate pollution during haze events in China, Nature, 514, 218-222, 2014.

Jackson, T. A., Muir, D. C. G., and Vincent, W. F.: Historical variations in the stable isotope composition of mercury in Arctic lake sediments, Environ. Sci. Technol., 38, 2813-2821, 2004.

Jackson, T. A., Whittle, D. M., Evans, M. S., and Muir, D. C. G.: Evidence for mass-independent and mass-dependent fractionation of the stable isotopes of mercury by natural processes in aquatic ecosystems, Appl. Geochem., 23, 547-571, 2008.

Jackson, T. A., Telmer, K. H., and Muir, D. C. G.: Mass-dependent and mass-independent variations in the isotope composition of mercury in cores from lakes polluted by a smelter: Effects of smelter emissions, natural processes, and their interactions, Chem. Geol., 352, 27-46, 2013.

Jackson, T. A.: Evidence for mass-independent fractionation of mercury isotopes by microbial activities linked to geographically and temporally varying climatic conditions in Arctic and subarctic Lakes, Geomicrobiol. J., 32, 799-826, 2015.

Jiskra, M., Wiederhold, J. G., Bourdon, B., and Kretzschmar, R.: Solution speciation controls mercury isotope fractionation of $\mathrm{Hg}(\mathrm{II})$ sorption to goethite, Environ. Sci. Technol., 46, 66546662, 2012.

Jiskra, M., Wiederhold, J. G., Skyllberg, U., Kronberg, R.-M., Hajdas, I., and Kretzschmar, R.: Mercury Deposition and Reemission Pathways in Boreal Forest Soils Investigated with $\mathrm{Hg}$ Isotope Signatures, Environ. Sci. Technol., 49, 7188-7196, 2015.

Kim, P. R., Han, Y. J., Holsen, T. M., and Yi, S. M.: Atmospheric particulate mercury: Concentrations and size distributions, Atmos. Environ., 61, 94-102, 2012.

Kim, S. H., Han, Y. J., Holsen, T. M., and Yi, S. M.: Characteristics of atmospheric speciated mercury concentrations (TGM, $\mathrm{Hg}$ (II) and $\mathrm{Hg}(\mathrm{p}))$ in Seoul, Korea, Atmos. Environ., 43, 3267-3274, 2009.

Li, J., Sommar, J., Wangberg, I., Lindqvist, O., and Wei, S. Q.: Short-time variation of mercury speciation in the urban of Goteborg during GOTE-2005, Atmos. Environ., 42, 8382-8388, 2008.
Lin, C. Y., Wang, Z., Chen, W. N., Chang, S. Y., Chou, C. C. K., Sugimoto, N., and Zhao, X.: Long-range transport of Asian dust and air pollutants to Taiwan: Observed evidence and model simulation, Atmos. Chem. Phys., 7, 423-434, doi:10.5194/acp-7-4232007, 2007.

Lin, H., Yuan, D., Lu, B., Huang, S., Sun, L., Zhang, F., and Gao, Y.: Isotopic composition analysis of dissolved mercury in seawater with purge and trap preconcentration and a modified $\mathrm{Hg}$ introduction device for MC-ICP-MS, J. Anal. Atom. Spectrom., 30, 353-359, 2015a.

Lin, Y.-C., Hsu, S.-C., Chou, C. C. K., Zhang, R., Wu, Y., Kao, S.J., Luo, L., Huang, C.-H., Lin, S.-H., and Huang, Y.-T.: Wintertime haze deterioration in Beijing by industrial pollution deduced from trace metal fingerprints and enhanced health risk by heavy metals, Environ. Pollut., 208, 284-293, 2015b.

Liu, B., Keeler, G. J., Dvonch, J. T., Barres, J. A., Lynam, M. M., Marsik, F. J., and Morgan, J. T.: Temporal variability of mercury speciation in urban air, Atmos. Environ., 41, 1911-1923, 2007.

Ma, J., Hintelmann, H., Kirk, J. L., and Muir, D. C. G.: Mercury concentrations and mercury isotope composition in lake sediment cores from the vicinity of a metal smelting facility in Flin Flon, Manitoba, Chem. Geol., 336, 96-102, 2013.

Malinovsky, D., Latruwe, K., Moens, L., and Vanhaecke, F.: Experimental study of mass-independence of $\mathrm{Hg}$ isotope fractionation during photodecomposition of dissolved methylmercury, J. Anal Atom. Spectrom., 25, 950-956, 2010.

Masbou, J., Point, D., Sonke, J. E., Frappart, F., Perrot, V., Amouroux, D., Richard, P., and Becker, P. R.: Hg stable isotope time trend in ringed seals registers decreasing sea ice cover in the Alaskan Arctic, Environ. Sci. Technol., 49, 8977-8985, 2015.

Mbengue, S., Alleman, L. Y., and Flament, P.: Size-distributed metallic elements in submicronic and ultrafine atmospheric particles from urban and industrial areas in northern France, Atmos. Res., 135, 35-47, 2014.

Nzihou, A. and Stanmore, B.: The fate of heavy metals during combustion and gasification of contaminated biomass: A brief review, J. Hazard. Mater., 256-257, 56-66, 2013.

Rolison, J. M., Landing, W. M., Luke, W., Cohen, M., and Salters, V. J. M.: Isotopic composition of species-specific atmospheric $\mathrm{Hg}$ in a coastal environment, Chem. Geol., 336, 37-49, 2013.

Rudnick, R., and Gao, S.: Composition of the continental crust, Treatise on Geochemistry, 3, 1-64, 2003.

Saleh, R., Robinson, E. S., Tkacik, D. S., Ahern, A. T., Liu, S., Aiken, A. C., Sullivan, R. C., Presto, A. A., Dubey, M. K., Yokelson, R. J., Donahue, N. M., and Robinson, A. L.: Brownness of organics in aerosols from biomass burning linked to their black carbon content, Nat. Geosci., 7, 647-650, 2014.

Schauble, E. A.: Role of nuclear volume in driving equilibrium stable isotope fractionation of mercury, thallium, and other very heavy elements, Geochim. Cosmochim. Acta, 71, 2170-2189, 2007.

Schleicher, N. J., Schäfer, J., Blanc, G., Chen, Y., Chai, F., Cen, K., and Norra, S.: Atmospheric particulate mercury in the megacity Beijing: Spatio-temporal variations and source apportionment, Atmos. Environ., 109, 251-261, 2015.

Seigneur, C., Abeck, H., Chia, G., Reinhard, M., Bloom, N. S., Prestbo, E., and Saxena, P.: Mercury adsorption to elemental carbon (soot) particles and atmospheric particulate matter, Atmos. Environ., 32, 2649-2657, 1998. 
Selin, N. E.: Global biogeochemical cycling of mercury: A review, Annu. Rev. Env. Resour., 34, 43-63, 2009.

Sherman, L. S., Blum, J. D., Johnson, K. P., Keeler, G. J., Barres, J. A., and Douglas, T. A.: Mass-independent fractionation of mercury isotopes in Arctic snow driven by sunlight, Nat. Geosci., 3, 173-177, 2010.

Sherman, L. S., Blum, J. D., Keeler, G. J., Demers, J. D., and Dvonch, J. T.: Investigation of local mercury deposition from a coal-fired power plant using mercury isotopes, Environ. Sci. Technol., 46, 382-390, 2012.

Sherman, L. S., Blum, J. D., Franzblau, A., and Basu, N.: New insight into biomarkers of human mercury exposure using naturally occurring mercury stable isotopes, Environ. Sci. Technol., 47, 3403-3409, 2013.

Sherman, L. S., Blum, J. D., Dvonch, J. T., Gratz, L. E., and Landis, M. S.: The use of $\mathrm{Pb}, \mathrm{Sr}$, and $\mathrm{Hg}$ isotopes in Great Lakes precipitation as a tool for pollution source attribution, Sci. Total Environ., 502, 362-374, 2015.

Smith, C. N., Kesler, S. E., Blum, J. D., and Rytuba, J. J.: Isotope geochemistry of mercury in source rocks, mineral deposits and spring deposits of the California coast ranges, USA, Earth. Planet. Sci. Lett., 269, 398-406, 2008.

Smith, R. S., Wiederhold, J. G., and Kretzschmar, R.: Mercury isotope fractionation during precipitation of metacinnabar $(\beta-\mathrm{HgS})$ and montroydite (HgO), Environ. Sci. Technol., 49, 4325-4334, 2015.

Song, S., Wu, Y., Jiang, J., Yang, L., Cheng, Y., and Hao, J.: Chemical characteristics of size-resolved $\mathrm{PM}_{2.5}$ at a roadside environment in Beijing, China, Environ. Pollut., 161, 215-221, 2012.

Song, Y., Tang, X. Y., Xie, S. D., Zhang, Y. H., Wei, Y. J., Zhang, M. S., Zeng, L. M., and Lu, S. H.: Source apportionment of PM2.5 in Beijing in 2004, J. Hazard. Mater., 146, 124-130, 2007.

Sonke, J. E.: A global model of mass independent mercury stable isotope fractionation, Geochim. Cosmochim. Acta, 75, 45774590, 2011.

Streets, D. G., Hao, J., Wu, Y., Jiang, J., Chan, M., Tian, H., and Feng, X.: Anthropogenic mercury emissions in China, Atmos. Environ., 39, 7789-7806, 2005.

Sun, G., Sommar, J., Feng, X., Lin, C.-J., Ge, M., Wang, W., Yin, R., Fu, X., and Shang, L.: Mass-Dependent and -Independent Fractionation of Mercury Isotope during Gas-Phase Oxidation of Elemental Mercury Vapor by Atomic $\mathrm{Cl}$ and $\mathrm{Br}$, Environ. Sci. Technol., 50, 9232-9241, 2016.

Sun, R., Sonke, J. E., Heimbürger, L.-E., Belkin, H. E., Liu, G., Shome, D., Cukrowska, E., Liousse, C., Pokrovsky, O. S., and Streets, D. G.: Mercury stable isotope signatures of world coal deposits and historical coal combustion emissions, Environ. Sci. Technol., 48, 7660-7668, 2014.

Sun, R. Y., Heimburger, L. E., Sonke, J. E., Liu, G. J., Amouroux, D., and Berail, S.: Mercury stable isotope fractionation in six utility boilers of two large coal-fired power plants, Chem. Geol., 336, 103-111, 2013.

Waheed, A., Li, X. L., Tan, M. G., Bao, L. M., Liu, J. F., Zhang, Y. X., Zhang, G. L., and Li, Y.: Size Distribution and Sources of Trace Metals in Ultrafine/Fine/Coarse Airborne Particles in the Atmosphere of Shanghai, Aerosol Sci. Technol., 45, 163-171, 2011

Wang, H., Kawamura, K., and Shooter, D.: Carbonaceous and ionic components in wintertime atmospheric aerosols from two New
Zealand cities: Implications for solid fuel combustion, Atmos. Environ., 39, 5865-5875, 2005.

Wang, L., Liu, Z., Sun, Y., Ji, D., and Wang, Y.: Long-range transport and regional sources of $\mathrm{PM}_{2.5}$ in Beijing based on longterm observations from 2005 to 2010, Atmos. Res., 157, 37-48, 2015a.

Wang, Z., Chen, J., Feng, X., Hintelmann, H., Yuan, S., Cai, H., Huang, Q., Wang, S., and Wang, F.: Mass-dependent and massindependent fractionation of mercury isotopes in precipitation from Guiyang, SW China, C. R. Geosci., 347, 358-367,2015b.

Wang, Z. W., Zhang, X. S., Chen, Z. S., and Zhang, Y.: Mercury concentrations in size-fractionated airborne particles at urban and suburban sites in Beijing, China, Atmos. Environ., 40, 2194 2201, 2006.

Wiederhold, J. G., Cramer, C. J., Daniel, K., Infante, I., Bourdon, B., and Kretzschmar, R.: Equilibrium mercury isotope fractionation between dissolved $\mathrm{Hg}$ (II) species and thiol-bound $\mathrm{Hg}$, Environ. Sci. Technol., 44, 4191-4197, 2010.

Won, J. H., Park, J. Y., and Lee, T. G.: Mercury emissions from automobiles using gasoline, diesel, and LPG, Atmos. Environ., 41, 7547-7552, 2007.

Xiu, G. L., Cai, J., Zhang, W. Y., Zhang, D. N., Bueler, A., Lee, S. C., Shen, Y., Xu, L. H., Huang, X. J., and Zhang, P.: Speciated mercury in size-fractionated particles in Shanghai ambient air, Atmos. Environ., 43, 3145-3154, 2009.

Xu, L. L., Chen, J. S., Niu, Z. C., Yin, L. Q., and Chen, Y. T.: Characterization of mercury in atmospheric particulate matter in the southeast coastal cities of China, Atmos. Pollut. Res., 4, 454461, 2013.

Xu, M., Yan, R., Zheng, C., Qiao, Y., Han, J., and Sheng, C.: Status of trace element emission in a coal combustion process: A review, Fuel Process. Technol., 85, 215-237, 2004.

Yin, R., Feng, X., and Shi, W.: Application of the stable-isotope system to the study of sources and fate of $\mathrm{Hg}$ in the environment: A review, Appl. Geochem., 25, 1467-1477, 2010.

Yin, R. S., Feng, X. B., and Meng, B.: Stable mercury isotope variation in rice plants (Oryza sativa $\mathrm{L}$.) from the Wanshan mercury mining district, SW China, Environ. Sci. Technol., 47, 22382245, 2013.

Yin, R. S., Feng, X. B., and Chen, J. B.: Mercury stable isotopic compositions in coals from major coal producing fields in China and their geochemical and environmental implications, Environ. Sci. Technol., 48, 5565-5574, 2014.

Yuan, S., Zhang, Y., Chen, J., Kang, S., Zhang, J., Feng, X., Cai, H., Wang, Z., Wang, Z., and Huang, Q.: Large variation of mercury isotope composition during a single precipitation event at Lhasa city, Tibetan Plateau, China, Procedia Earth and Planetary Science, 13, 282-286, 2015.

Zambardi, T., Sonke, J. E., Toutain, J. P., Sortino, F., and Shinohara, H.: Mercury emissions and stable isotopic compositions at Vulcano Island (Italy), Earth. Planet. Sci. Lett., 277, 236-243, 2009.

Zhang, H., Yin, R. S., Feng, X. B., Sommar, J., Anderson, C. W. N., Sapkota, A., Fu, X. W., and Larssen, T.: Atmospheric mercury inputs in montane soils increase with elevation: Evidence from mercury isotope signatures, Sci. Rep., 3, 3322, doi:10.1038/srep03322, 2013a.

Zhang, L., Wang, S. X., Wang, L., and Hao, J. M.: Atmospheric mercury concentration and chemical speciation at a rural site in Beijing, China: implications of mercury emission sources, 
Atmos. Chem. Phys., 13, 10505-10516, doi:10.5194/acp-1310505-2013, 2013b.

Zhang, L., Wang, S. X., Wang, L., Wu, Y., Duan, L., Wu, Q. R., Wang, F. Y., Yang, M., Yang, H., Hao, J. M., and Liu, X.: Updated emission inventories for speciated atmospheric mercury from anthropogenic sources in China, Environ. Sci. Technol., 49, 3185-3194, 2015.

Zhang, Y., Schauer, J. J., Zhang, Y., Zeng, L., Wei, Y., Liu, Y., and Shao, M.: Characteristics of particulate carbon emissions from real-world Chinese coal combustion, Environ. Sci. Technol., 42, 5068-5073, 2008.

Zheng, M., Salmon, L. G., Schauer, J. J., Zeng, L., Kiang, C. S., Zhang, Y., and Cass, G. R.: Seasonal trends in $\mathrm{PM}_{2.5}$ source contributions in Beijing, China, Atmos. Environ., 39, 3967-3976, 2005a.

Zheng, W. and Hintelmann, H.: Mercury isotope fractionation during photoreduction in natural water is controlled by its $\mathrm{Hg} / \mathrm{DOC}$ ratio, Geochim. Cosmochim. Acta, 73, 6704-6715, 2009.
Zheng, W. and Hintelmann, H.: Isotope fractionation of mercury during its photochemical reduction by low-molecular-weight organic compounds, J. Phys. Chem. A, 114, 4246-4253, 2010a.

Zheng, W. and Hintelmann, H.: Nuclear field shift effect in isotope fractionation of mercury during abiotic reduction in the absence of light, J. Phys. Chem. A, 114, 4238-4245, 2010 b.

Zheng, W., Foucher, D., and Hintelmann, H.: Mercury isotope fractionation during volatilization of $\mathrm{Hg}(0)$ from solution into the gas phase, J. Anal. At. Spectrom., 22, 1097-1104, 2007.

Zheng, X., Liu, X., Zhao, F., Duan, F., Yu, T., and H, C.: Seasonal characteristics of biomass burning contribution to Beijing aerosol, Sci. China Ser. B, 48, 481-488, 2005b.

Zhou, J., Zhang, R., Cao, J., Chow, J. C., and Watson, J. G.: Carbonaceous and ionic components of atmospheric fine particles in Beijing and their impact on atmospheric visibility, Aerosol Air Qual. Res., 12, 492-502, 2012.

Zhu, J., Wang, T., Talbot, R., Mao, H., Yang, X., Fu, C., Sun, J., Zhuang, B., Li, S., Han, Y., and Xie, M.: Characteristics of atmospheric mercury deposition and size-fractionated particulate mercury in urban Nanjing, China, Atmos. Chem. Phys., 14, 2233 2244, doi:10.5194/acp-14-2233-2014, 2014. 